\title{
LA DIRECCIÓN GENERAL DE BELLAS ARTES REPUBLICANA Y SU REITERADA GESTIÓN POR RICARDO DE ORUETA (1931-1936)
}

\author{
POR \\ Miguel Cabañas Bravo \\ Instituto de Historia, CCHS, CSIC
}

\begin{abstract}
El autor analiza la gestión de la política artística que llevó a cabo en la Dirección General de Bellas Artes el historiador del arte Ricardo de Orueta (Málaga, 1868-Madrid, 1939), durante los dos trascendentes períodos de la Segunda República en los fue su responsable (de abril de 1931 a diciembre de 1933 y de febrero a septiembre de 1936). En ambos, se impuso inmediatamente la salvaguarda de nuestro patrimonio artístico y el afán por su documentación, su catalogación y la creación de estructuras administrativas que lo estudiaran y preservaran. La pionera gestión de Orueta, además, tuvo un gran alcance, ya que no sólo fue la que puso en marcha las primeras y más trascendentes medidas artísticas republicanas, como la perdurable Ley del Tesoro Artístico de 1933, sino también, con el estallido de la Guerra Civil, a la que correspondió hacer frente por segunda vez a los excesos iniciales contra el patrimonio histórico-artístico.
\end{abstract}

Palabras clave: Ricardo de Orueta; Política artística; Patrimonio histórico-artístico; Segunda República española; Guerra Civil española.

The author analyzes the management of artistic politics carried out by art historian Ricardo de Orueta (Málaga, 1868-Madrid, 1939) at the Dirección General de Bellas Artes during the two significant periods of the Second Republic when he was in charge, from April 1931 to December 1933 and from February to September 1936. At both times the government immediately imposed the safekeeping of the Spanish artistic patrimony, combined with its documentation through cataloguing and the formation of administrative structures for its study and preservation. Orueta's pioneering management measures were far-reaching given that they not only set in motion the first and most transcendent artistic measures of the Republic (eg: the long-lasting 1933 Ley del Tesoro Artístico), but also, with the outbreak of the Spanish Civil War, confront for the second time initial excesses against the historical-artistic patrimony.

Key words: Ricardo de Orueta; Artistic politics; Historical-artistic patrimony; Second Spanish Republic; Spanish Civil War.

La creación en 1900 del Ministerio de Instrucción Pública y Bellas Artes ${ }^{1}$-en adelante MIPBA-, al cual, entre otras atribuciones, se le confirieron las concernientes a "Bellas Artes,

\footnotetext{
${ }^{1}$ Real Decreto de 18-IV-1900, Gaceta de Madrid, n. ${ }^{\circ}$ 109, de 19-IV-1900.
} 
Archivos, Bibliotecas y Museos", trajo consigo el pronto establecimiento en su seno de la Dirección General de Bellas Artes -en adelante DGBA-, con objeto de que rigiera y gestionara esos cometidos. Con la llegada de la Segunda República en 1931, sus obligaciones no variaron mucho, aunque sí hubo, además de un renovado impulso que reactivó las estructuras, un serio cambio de orientación e ideario, seguido de múltiples nuevas regulaciones y reordenaciones de la gestión y de crecientes reestructuraciones y transferencia de competencias.

El piloto pionero de estas transformaciones republicanas en el seno de la DGBA fue el historiador del arte Ricardo de Orueta y Duarte (Málaga, 1868-Madrid, 1939), viejo republicano, afín a los institucionistas e investigador sobre escultura en la Sección de Arte del Centro de Estudios Históricos (CEH) (fig. 1) de la Junta para Ampliación de Estudios (JAE), quien durante aquellos agitados años de andadura de la joven República, fue elevado al cargo de director general de Bellas Artes en dos ocasiones, diferentes y de gran trascendencia, en las cuales se impuso de inmediato la salvaguarda de nuestro patrimonio artístico -o, como solía denominarse entonces, de nuestro "Tesoro Artístico"-, sin descuidar el afán por su documentación, su catalogación y la creación de estructuras administrativas que lo estudiaran y preservaran. Su responsabilidad en la nueva política artística que ahora se fraguó, además, fue manifiesta y de especial alcance, puesto que, ciertamente, el historiador malagueño no sólo fue en 1931 el primer director general Bellas Artes que tuvo la Segunda República y quien puso en marcha algunas de sus más interesantes medidas en el ámbito artístico - como, entre otras, la tan perdurable Ley del Tesoro Artístico de 1933, que estuvo en vigor hasta 1985-, sino que en 1936 también fue, nuevamente, el primero del período bélico e, igualmente, a quien correspondió hacer frente por segunda vez a los excesos iniciales contra el patrimonio histórico-artístico, para lo que le fue muy útil la experiencia anterior y las medidas legislativas fomentadas entonces.

Con todo, la figura y actuación de este comprometido e influyente historiador del arte, cuyos esquemas conductores principalmente fueron los heredados del regeneracionismo y el institucionismo, parecen haber caído demasiado en el olvido de nuestra reciente historiografía; así como prácticamente se desconoce el Fondo Documental Ricardo de Orueta, conservado hoy

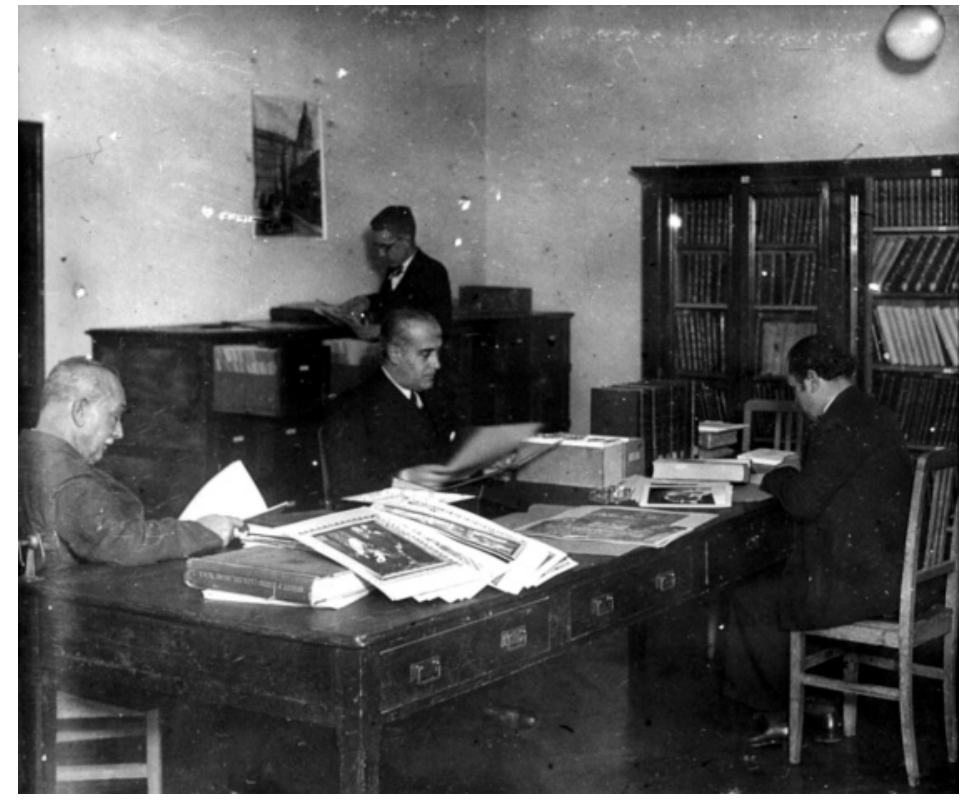

Fig. 1. Orueta y Sánchez Cantón, sentados, en el Fichero de Arte Antiguo y Fototeca del CEH; c.1931. (Archivo CCHS). 
en el Archivo del Centro de Ciencias Humanas y Sociales (CCHS) del CSIC ${ }^{2}$ y que, precisamente, contiene su correspondencia personal durante esos dos periodos en los estuvo al frente de la DGBA. Ya hemos dedicado atención a las características de este último fondo documental y a la formación, la producción y el bagaje del erudito malagueño en otros lugares ${ }^{3}$, lo que nos complementará el contexto de lo que aquí expondremos, que esencialmente se centra en el análisis concreto de la actuación de Ricardo de Orueta durante los dos periodos en los que fue responsable de la DGBA. También nos apoyaremos para ello en la complementaria documentación, de carácter más burocrático, conservada en el Archivo General de la Administración (AGA) de Alcalá de Henares.

\section{El primer período de Orueta al frente de la DGBA (abril 1931-diciembre 1933)}

El 23 de abril de 1931 el Gobierno Provisional republicano nombraba al primer director general de Bellas Artes del nuevo régimen, el historiador del arte malagueño Ricardo de Orueta y Duarte, quien prácticamente sucedía en el cargo a su maestro y compañero del CEH Manuel Gómez Moreno, aunque su labor, hasta que dejara la responsabilidad el 26 de diciembre de 1933, sería más amplia y trascendente que la del erudito granadino ${ }^{4}$, e incluso habría de repetirse.

Aparte del mismo sesgo institucionista que dio a su gestión, Orueta hubo de comenzar su labor con el Gobierno Provisional haciendo frente a las primeras reorganizaciones ministeriales y departamentales que aplicó la República a través de diferentes decretos, pero sobre todo comenzó su tarea intentando evitar desmanes contra el patrimonio histórico-artístico, como los iniciales que aparejó la proclamación de la Segunda República ${ }^{5}$ (fig. 2) o las posibilidades de expolio que representaba la venta de bienes por parte del clero y la nobleza; lo cual, ya desde estos momentos, le llevó a promover diferentes e importantes medidas legislativas para su preservación y el aumento de competencias de su departamento.

\footnotetext{
${ }^{2}$ Proviene del antiguo Instituto Diego Velázquez del CSIC y su actual denominación, dentro del Archivo del CCHS, es Archivo Textual-Fondo Ricardo de Orueta, que en adelante citaremos: ACCHS, AT-Orueta.

${ }^{3}$ Cabañas Bravo, M.: "Ricardo de Orueta y la Dirección General de Bellas Artes durante la II República y la guerra civil", en el volumen colectivo Cabañas, M.; López-Yarto, A. y Rincón, W. (coords.): Arte en tiempos de guerra (Madrid, CSIC, 2009), que corresponde a nuestra comunicación en las XIV Jornadas Internacionales de Historia del Arte: Arte en tiempos de guerra (Madrid, CCHS, noviembre 2008). Por otro lado, ambos trabajos, complementarios, entroncan con el proyecto Arte y artistas españoles dentro y fuera de la dictadura franquista (MICINN, PN 2008-2011, Ref. HAR2008-00744).

${ }^{4}$ El nombramiento de Gómez Moreno para este puesto durante el Gobierno del general Berenguer, tuvo que ver con el acceso en 1930 de Elías Tormo (también maestro y compañero de Orueta en el CEH) al cargo de ministro de Instrucción Pública. Gómez Moreno, sin embargo, se dedicó más a la labor científica e incluso, ante sus ausencias, delegó la firma en Tormo (véase Real Orden n. ${ }^{\circ}$ 1516, de 4-VIII-1930, Gaceta de Madrid, n. ${ }^{\circ}$ 217, de 5-VIII-1930, p. 852). De este modo, al año siguiente, cuando ocupó la cartera el ministro José Gascón, Gómez Moreno presentó su dimisión; siendo efímeramente sustituido en el puesto, desde la misma fecha, por José Joaquín Herrero, ex subsecretario del MIPBA (respectivamente, Reales Decretos n. ${ }^{\circ} 775$ y 776 de 27-II-1931, Gaceta de Madrid, n. ${ }^{\circ}$ 58, de 27-II-1931, p. 1141). En cuanto al nombramiento de Orueta, fue realizado por Alcalá-Zamora, presidente del Gobierno Provisional, a propuesta del ministro del MIPBA Marcelino Domingo, por Decreto de 23-IV-1931 (Gaceta de Madrid, n. ${ }^{\circ}$ 114, de 24-IV-1931, p. 303). Orueta hizo llegar su dimisión al mismo presidente con el nuevo titular de la cartera, José Pareja, el 26-XII-1933 (Gaceta de Madrid, n. ${ }^{\circ} 361$, de 27-XII-1933, p. 2172).

${ }^{5}$ En los días 11 y 12 de mayo de 1931 fueron incendiados por manifestantes, cuyos propósitos nunca quedaron bien aclarados, varios conventos madrileños y 22 iglesias y conventos malagueños. En Madrid, el ministro de Gobernación Miguel Maura, pudo impedir que continuaran estos excesos y que se reprodujeran en otras ciudades, aunque fue imposible en Málaga por la incapacidad de sus gobernadores civil y militar.
} 


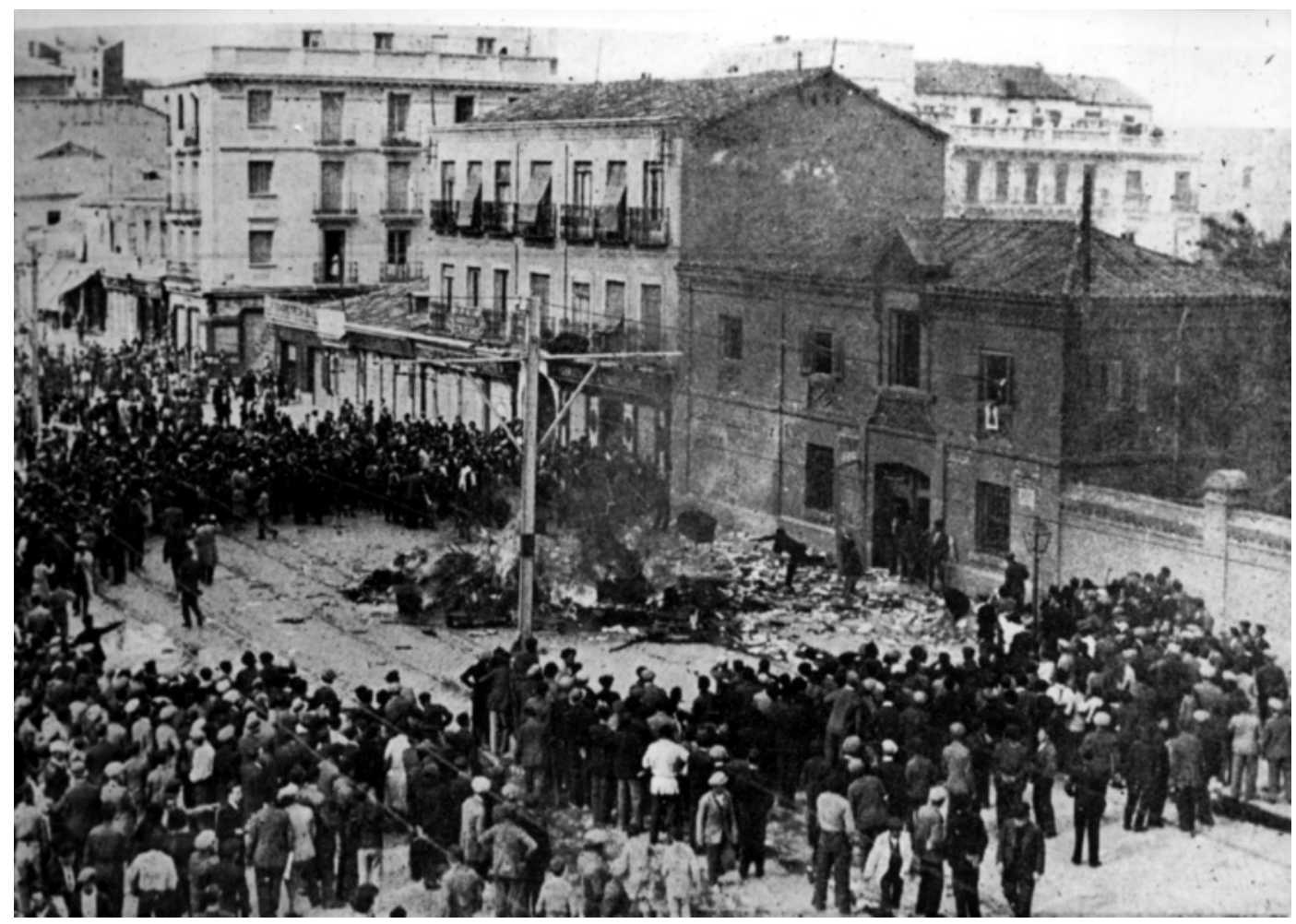

Fig. 2. Incendio y saqueo del Colegio de las Maravillas de Madrid, 1931 (AGA).

Entre algunas de las propuestas que más cerca parecen haber tenido su impulso durante esta etapa constituyente, que duraría hasta mediados de octubre de 1931, podemos identificar, por tanto, varias medidas de orden normativo que desembocarían en la trascendental Ley del Tesoro Artístico de 1933, entre las que se encuentran:

-Decreto de 22-V-1931, que reguló la enajenación de inmuebles y objetos artísticos, históricos o arqueológicos, sin previa autorización del MIPBA -en el caso de los objetos muebles- y sin el preceptivo informe de la DGBA -en caso de los inmuebles.

- Decreto de 27-V-1931, que, intentando evitar la pérdida o el deterioro de obras de arte, establecía para las obras que estuvieran en peligro el procedimiento para su incautación y depósito en los Museos Provinciales o en los Museos Nacionales. Fue el Decreto en el que, cuando estallara la guerra, se apoyó Orueta para disponer las primeras medidas y actuaciones administrativas de incautación.

- Decreto de 29-V-1931, que declaraba gratuita la entrada, para los profesores de todas las categorías y los alumnos que les acompañaran, a los monumentos nacionales, museos y centros artísticos dependientes del MIPBA.

-Decreto del 13-VII-1931 por el que se encomendó al CEH y sus Secciones de Arte y Arqueología la formación de un Fichero de Arte Antiguo (fig. 1), que recogiera y documentara todas las obras de arte anteriores a 1850 del territorio nacional, así como que informara preceptivamente en los expedientes de expoliación, venta o exportación indebidas y formara un inventario de las obras de arte destruidas o exportadas desde 1875; que fue una iniciativa 
especial de Orueta, como se recoge en el propio texto y expondrá también Orueta en su correspondencia ${ }^{6}$.

-Decreto del 3-VII-1931, que prohibió temporalmente la exportación de objetos artísticos, arqueológicos o históricos, autorizando la venta dentro de España entre particulares, siempre que se hubiera comunicado a la Administración. La Orden del MIPBA de 11-VII-1931 aclaró los límites de la exportación, estableciendo que sólo afectaría a los bienes que tuvieran un precio superior a las 50.000 ptas., y, las Cortes Constituyentes, convirtieron estas normativas en la Ley de 10-XII-1931, que reguló la enajenación de este tipo de bienes muebles e inmuebles (sólo referida a los que se consideraran con una antigüedad mayor a cien años), estableció el derecho de tanteo a favor del Estado y actualizó la vigencia de la ley desamortizadora que impedía a la Iglesia ser propietaria de sus bienes.

- También, por otro lado, es significativo que, con la Ley de 15-IX-1931, que declaró Monumento nacional al Misterio de Elche, se actuó por primera vez en España en materia de salvaguarda de los bienes etnográficos.

Con todas estas disposiciones ${ }^{7}$, ya el Gobierno Provisional hizo de la DGBA el eje y centro gestor más importante en materia de patrimonio-histórico artístico, aumentando las competencias que tenía su director, cuyo cargo había venido perdiendo peso político y capacidad de acción administrativa durante el régimen anterior, en el que habían preponderado los puestos honoríficos y poco ejecutivos. De esta manera, aparte de las variadas propuestas salidas del departamento de Orueta, que simplemente se presentaban a la aprobación del ministro ${ }^{8}$, ahora recibió nuevas atribuciones, especialmente de carácter consultivo, como es el caso de la enajenación de inmuebles histórico-artísticos o la decisión de incautar y depositar en museos los bienes en peligro, el conocimiento de la venta de bienes entre particulares en España o la petición de informes científicos.

Por otro lado, entre los nombramientos y fundaciones o transformaciones de los centros dependientes de la DGBA, destaca la creación, por Decreto de 1-IX-1931, del puesto y función de Conservador General del Tesoro Artístico Nacional, que recayó sobre Ramón del Valle-Inclán. Parecía un cargo creado a medida de las necesidades de éste, quien ejerció muy poco la labor de información, vigilancia y divulgación sobre los monumentos que se preveían, de manera que el puesto fue variando de contenido ${ }^{9}$. El Gobierno Provisional también dejó vacante la dirección

${ }^{6}$ Decreto publicado en la Gaceta de Madrid n. ${ }^{\circ}$ 195, de 14-VII-1931. Orueta hará varias alusiones a ello al remitir la primera publicación del Fichero, como en el caso de su envío a Manuel Zabala, Secretario de la Academia de San Fernando (Carta de 19-VII-1932. ACCHS, AT-Orueta, Caja 1154-1, 331).

7 Sobre su contexto y referentes bibliográficos, véase CABAÑAS Bravo, M.: "Ricardo de Orueta...", op. cit., 2009. Son especialmente interesantes, en su conjunto, las síntesis complementarias de TusELl, Javier: Arte, historia y política en España (1980-1939), Madrid, Biblioteca Nueva, 1999 y FERNÁNDEZ GARCíA, Javier: "La regulación y la gestión del patrimonio histórico-artístico durante la Segunda República (1931-1939), e-rph. Revista Electrónica de Patrimonio Histórico, n. ${ }^{\circ}$ 1, diciembre 2007, ISSN 1988-7213 (recurso: http://www.revistadepatrimonio.es/revistas/numero1/_e-rdep_1.pdf).

${ }^{8}$ Así, por ejemplo, entre su correspondencia con el ministro Marcelino Domingo, figuran notas como la que le enviaba el 13-VII-1931 indicándole: "Por no molestarle más no subo personalmente y le envío los Decretos que le leí esta mañana y que se dignó aprobar./ Le recuerdo la necesidad de que quedasen hoy aprobados el de los Auxiliares de Artes y Oficios, Fichero Artístico, Museo Arqueológico y también me permito recordarle mi pase para la Asamblea Constituyente." (ACCHS, AT-Orueta, Caja 1149-1, Exp.021, 149).

9 Hay que aclarar que, en agosto de 1931, Valle-Inclán pasaba graves apuros económicos, planteándose emigrar a América. Azaña y su Consejo de Ministros decidieron buscarle un cargo remunerado, que fue éste. Orueta le informó de que su cometido principal sería escribir monografías, a lo que Valle Inclán contestó enfurecido que esa ocupación era para escritores fracasados y que él no era un mendigo de la República; incidente que hizo redefinir su función e ir buscándole otro puesto. Aunque el cargo siguió siendo recogido en la Ley de 8-I-1932 y la de 11-3-1932, cuando realmente se le asignó una función concreta fue en el Decreto de 27-I-1932, que la fijaba en organizar y dirigir el Museo 
de la recién recreada Inspección General de Monumentos, que hasta su dimisión, recogida en el Decreto de 18-V-1931, había ocupado Diego Angulo. Otro Decreto de la misma fecha, asignó temporalmente ese cargo al Director General de Bellas Artes, aunque lo volvió a ocupar Angulo entre noviembre de 1931 y abril de $1932^{10}$. Finalmente, las funciones de los Delegados Provinciales de Bellas Artes quedaron reguladas por el Decreto de 11-VIII-1931, que también les convertía en vocales natos de las Comisiones Provinciales de Monumentos y cuyos nombramientos y ceses fueron constantes.

Por otra parte, en cuanto a la gestión y conservación de los monumentos y conjuntos histórico-artísticos, uno de los decretos más notables y eficaces que aprobó el Gobierno Provisional fue el de 4-VI-1931, por el que 731 obras fueron declaradas monumentos histórico-artísticos pertenecientes al Tesoro Nacional, lo cual incluía iglesias, monasterios, castillos, murallas, despoblados, yacimientos y palacios. La medida no tenía precedentes de tanto alcance, pues los inmuebles declarados anteriormente apenas si llegaban al centenar y no incluían todas las provincias, como ocurriría a partir de ahora. Además, en su proyecto de estructurar y depurar el antiguo Patrimonio de la Corona y pasarlo, cuando fuera posible, a la gestión y disfrute de los municipios y sus ciudadanos, estuvieron el Decreto de 22-IV-1931, por el que al Municipio de Sevilla se le cedía el Alcázar y al de Barcelona el Palacio de Pedralbes, y la Ley de 9-IX-1931, por la que el Bosque y Palacio de Bellver se cedieron al Ayuntamiento de Palma de Mallorca para que se hicieran un parque municipal y un museo de arte antiguo.

Además de la promoción de la realización de inventarios y catálogos, de las declaraciones monumentales, de la ampliación de disfrute del antiguo patrimonio de la Corona y de la creación de patronatos como formula principal de gestión de los archivos, bibliotecas y museos dependientes del departamento, estuvo el propio nombramiento de directores, subdirectores y vocales de estos órganos de gestión. Entre los centros museísticos, el más temprano al que se dotó de nueva dirección fue el Museo del Prado, para el que, con cierta precipitación, en el Decreto de 13-V-1931 se nombró director a Ramón Pérez de Ayala, pero como también había sido designado embajador de España en Londres, el nuevo Decreto de 18-V-1931 le reservó el cargo, le autorizó a ausentarse y ordenó que ocupara el puesto interinamente Francisco Javier Sánchez Cantón. Por el Decreto de 28-VIII-1931, además, aumentó su Patronato con dos vocales más, entre ellos Gregorio Marañón. No es extraño, pues, que artistas como Ricardo Baroja, en su correspondencia con Orueta y dimitiendo de su "carguito de Profesor Interino de Tipografía Artística en la Escuela de Artes Gráficas", se queje amargamente de la política de nombramientos honoríficos que estaba iniciando la República: “Todo está contribuyendo a mi desilusión republicana -le dirá-. Mi deseo más ferviente es no colaborar con nada del Estado, es más, mi intención es combatirlo con todas mis fuerzas. Se parece a la monarquía esta república, como se parecen dos gotas de agua, algunas veces se parecen como dos gotas de sangres o dos gotas de pus (...)./ La República que pone a Pérez de Ayala al frente del Museo del Prado y que ha señalado a Valle-Inclán como posible Director del Museo de Arte Moderno está ya calificada, porque ninguno de los dos sabe

del Real Sitio de Aranjuez. El Decreto de 7-IV-1932, a lo que parece por error, aceptaba la dimisión del cargo a Diego Angulo, que en realidad dimitía como Inspector General de Monumentos. Por el Decreto de 8-III-1933, se nombró a Valle-Inclán director de la Academia Española de Bellas Artes en Roma. Previamente, Ignacio Zuloaga pidió a Orueta (carta de 12-10-1932) que apoyara este nombramiento, a lo que el malagueño le respondió (22-10-1932) que contribuiría con lo que pudiera, aunque no dependía de él (ACCHS, AT-Orueta, Caja 1154-1, 407-408).

10 Decretos de 13-XI-1931 y 7-IV-1932, respectivamente, de nombramiento y dimisión. La correspondencia entre Orueta, Carreño y Angulo también alude a las razones de la designación (pues primero se pensó en Gómez Moreno, pero no pudo ser por circunstancias políticas) y de la dimisión. (Véase cartas de Carreño a Angulo de 3-12-1931 y 164-1932. Caja 1147-80, exp. 560-566.) A partir de a Ley de 13-IV-1933, el cargo quedó adscrito a la Junta Superior del Tesoro Artístico, y lo desempeñaría uno de sus vocales. 
una palabra de arte, ni jamás les ha interesado ni la Pintura, ni la Escultura, y los dos han mostrado más palmariamente su incapacidad. Pues lo mismo ocurre con muchos de los nombres para figurar en los Patronatos de los museos"11.

Este tipo de críticas iniciales serían muy útiles para que, en adelante, se intentara afinar más. No obstante, otro problema difícil que se plantearía de inmediato sería el de los nombramientos para el Museo de Arte Moderno, cuyo Patronato había planteado una dimisión colectiva, que fue aceptada y se nombró otro en sendos decretos de 27-V-1931. Además, se aprovechó la circunstancia para, en un tercer decreto de la misma fecha, renovar vocales. Pero al comenzar a funcionar este órgano, surgieron nuevos problemas entre sus miembros y la dimisión de casi todos, por lo que se suspendió temporalmente su funcionamiento y se nombró un delegado del Gobierno para dirigir el Museo, el pintor Eduardo Chicharro, al tiempo que se aceptaba la dimisión de Mariano Benlliure como director del mismo (Decretos de 3-VII-1931). Finalmente, mediante ocho decretos más de 31-VII-1931, se nombró tanto nuevo director a Ricardo Gutiérrez Abascal (Juan de la Encina), que era el anterior subdirector, como a Timoteo Pérez Rubio para el puesto que éste dejaba; al igual que se aceptó la dimisión de un vocal, se designaron dos nuevos y se convirtió a Benlliure en director honorario. Tampoco resultaría raro, por tanto, que, en medio de este agrio proceso, en el que Orueta pediría a Valle-Inclán que correspondiera "con el sacrificio" de mantenerse como vocal del Patronato ${ }^{12}$, ahora fuera el pintor Ignacio Zuloaga quien dijera al malagueño: "Supongo que ya por fin habrá Vd. arreglado el Patronato del Museo Moderno. Yo salí asustado. Nunca creí que entre los artistas españoles hubiera tan poca fraternidad... de buena me he salvado!"; y no volvería a aceptar los nuevos nombramientos que le propuso ${ }^{13}$.

La creación de otros nuevos Patronatos y la elección de cargos para otros tantos museos durante el Gobierno Provisional fue, por contraste, menos polémica; como fueron los casos de la temprana designación del Patronato del Museo Sorolla -al que perteneció siempre Orueta- y la aprobación de su reglamento (Decretos de 29-V-1931 y 10-VII-1931); el del cambio de régimen y creación del Patronato para el Museo Arqueológico Nacional (Decreto de 10-VII-1931); o, en fin, el del nombramiento de los vocales -en los que se dio entrada a obreros designados por la Casa del Pueblo de Madrid- del Museo Nacional de Artes Decorativas (Decretos de 10 y 17-VII-1931 y 6-X-1931).

Mas con ser amplia y decidida esta primera labor, lo más sustantivo y trascendente de la actuación normativa republicana sobre protección del patrimonio y promoción artística, se dio durante el bienio reformista (octubre 1931-septiembre 1933), en el que Orueta tuvo como jefe responsable de la cartera, durante la mayor parte del tiempo, a Fernando de los Ríos (del 16-XII-1931 al 12VI-1933), quien prestaría una atención muy estimable a estos temas y sacaría adelante algunas de las medidas republicanas más importantes. No obstante, previamente, todavía con su predecesor Marcelino Domingo ocupando la cartera, durante los primeros meses de esta etapa reformista se precisaron o culminaron algunas significativas actuaciones ya iniciadas en el anterior Gobierno. Hay que destacar, entre éstas, la Ley de 23-X-1931, por la que se crearían los Patronatos directivos e inspectores de varios de los archivos históricos más destacados (Histórico Nacional, Indias, Simancas y Corona de Aragón) y se pondrían las bases para crear los de cuantos archivos, bibliotecas

11 Carta fechada en Madrid el 29-VI-1931. En su contestación, de 10-IX-1931, Orueta le dirá que lamenta su decisión y que no intentará disuadirle ante los problemas de salud que también alega (ACCHS, AT-Orueta, Caja 1147-3, Exp. 155, 1105-1108).

12 Carta de 26-V-1931, en la que le argumentaba a Valle-Inclán: “... no puedo prescindir de Vd. para el Patronato del Museo de Arte Moderno. Por encima de chismografías y mezquindades el nombre de Vd., gloria legítima de España, se impone a todos y yo no me considero con derecho a privar a nuestra República de tan excelsa colaboración." (ACCHS, AT-Orueta, Caja 1154-1, 97).

${ }^{13}$ Carta fechada en Zumaya, el 12-VII-1931. En sus telegramas a Orueta desde París de 22-II-1932, Zuloaga le agradecerá, pero no aceptará su nombramiento de académico (ACCHS, AT-Orueta, Caja 1154-1, 410-415). 
y museos estimara necesario el ministro del ramo. Lo cual, además de la regulación de la incorporación de los protocolos notariales con más de un siglo de antigüedad a los Archivos Históricos Provinciales (Decreto de 12-XI-1931), se seguiría de la aparición de diferentes decretos reformando o creando Patronatos como órganos de gestión en diferentes establecimientos. Fue el caso inmediato, por ejemplo, de la aparición de dos decretos de 17-XI-1931, mediante los que se creó y dotó de vocales al Patronato del Monasterio de las Santas Creus tarraconense ${ }^{14}$. Por otro lado, en la línea anterior de protección, aunque mucho más moderadamente, continuaron las declaraciones de monumentos histórico-artísticos, como las de los monasterios oscenses de Santa Cruz de la Serós y San Pedro de Sirena (Orden de 13-XI-1931). Igualmente, mediante la citada Ley de 10-XII-1931 (alusiva a los requisitos de cien años de antigüedad e informes preceptivos y al derecho de tanteo y propiedad de los bienes de la Iglesia), se regularían las ventas de inmuebles y objetos artísticos. Con todo, sin duda la quintaesencia de la orientación que guió toda la labor reestructuradora y reformadora habida hasta entonces en materia de protección de nuestro patrimonio histórico-artístico, se vería reflejada en el novedoso y avanzado artículo 45 de la nueva Constitución promulgada el 9 de diciembre de 1931, el cual establecería: "Toda la riqueza artística e histórica del país, sea quien fuere su dueño, constituye el tesoro cultural de la Nación, y estará bajo la salvaguardia del Estado, que podrá prohibir su exportación y enajenación y decretar las expropiaciones legales que estimare oportunas para su defensa. El Estado organizará un registro de la riqueza artística e histórica, asegurará su celosa custodia y atenderá a su perfecta conservación. El Estado protegerá también los lugares notables por su belleza natural o por su reconocido valor artístico o histórico".

Ya con Fernando de los Ríos a la cabeza del MIPBA, desde el departamento de Orueta saldrían, a partir de comienzos de 1932, otras importantes medidas. Una de las primeras fue la Circular de 1-II-1932 dirigida por éste a todos los Gobernadores Civiles -para que se lo hicieran saber a los alcaldes-, prohibiendo la colocación de soportes para cables eléctricos y telefónicos en los monumentos histórico-artísticos ${ }^{15}$. Otras normas, como el Decreto de 19-V-1932, se dirigieron a reestructurar, regular y modernizar la administración y cometidos del cuerpo de archiveros, bibliotecarios y arqueólogos-museólogos. Y prueba, en otro orden, del temprano y continuado interés que tuvo Orueta por la puesta al día con las medidas internacionales respecto al tema museístico y la conservación y protección de las obras de arte, es su correspondencia y contactos, entre septiembre de 1931 y diciembre de 1933, con el secretario general en París de la Oficina Internacional de Museos de la Sociedad de Naciones, Euripide Foundoukidis; una personalidad que, con su posterior acercamiento durante la guerra al sucesor de Orueta, Josep Renau, de nuevo jugaría un importante papel internacional en la difusión de las medidas de protección de nuestro patrimonio ${ }^{16}$. Los primeros contactos, no obstante, tuvieron inicio ahora a través de Orueta y las invitaciones de dicho secretario a participar en congresos (como el celebrado en París en octubre de 1931, al cual envió la DGBA una delegación compuesta por López Otero, Torres Balbás, Moya y Arrate), en revistas como Mouseion (recién puesta en pié por la citada Oficina) o en reuniones de expertos, como a la que acudió Orueta en París en noviembre de 1933, con objeto de crear una Comisión Internacional de Monumentos Históricos ${ }^{17}$.

${ }^{14}$ La rapidez que Orueta intentó dar a este asunto provenía, como le dirá en su carta de 16-VIII-1932 al Secretario General de la Academia de San Fernando, de la "necesidad de cumplir compromisos políticos y de Gobierno antes de que sea Ley el Estatuto de Cataluña" (ACCHS, AT-Orueta, Caja 1154-1, 331).

15 Publicada en la Gaceta de Madrid n. ${ }^{\circ}$ 34, de 3-II-1932. Entre otras referencias en la documentación de Orueta, véase la minuta de 1-II-1932 (ACCHS, AT-Orueta, Caja 1148-2, 167-0842).

16 Véase Cabañas Bravo, Miguel: Josep Renau, arte y propaganda en guerra, Madrid, Ministerio de Cultura, 2007, pp. 79-82, 183.

17 ACCHS, AT-Orueta, Caja 1152-1, 0137-0144. Sobre la divulgación internacional de la labor de la DGBA y otros contactos de Orueta con Foundoukidis y su estancia de noviembre de 1933 en París, véase su correspondencia 
No sería tan concienzuda y brillante, en cambio, la gestión de Orueta en torno al arte contemporáneo vanguardista. Cierto que, con él, se intentó dar un tono más avanzado a los jurados calificadores de la Exposición Nacional de 1932 (Decreto de 23-IV-1932), apareciendo en ellos artistas como Sunyer, Emiliano Barral, Ángel Ferrant o Manuel Sánchez Arcas ${ }^{18}$. Es verdad también la importancia concedida a la promoción exterior de este arte nuestro, especialmente en París, lo que le llevó a impulsar, con la designación de un significativo comité, una Exposición de Arte Español ideada por Manuel Abril y Juan de la Encina, que se pensaba celebrar allí en junio de 1933, aunque Orueta finalmente la retrasaría a noviembre, ante el temor de que el nuevo ministro no lo confirmara o no deseara continuar con el proyecto ${ }^{19}$. Una actuación que se complementó, en la misma línea, con el intento de dar a conocer en su país, atrayéndolas para exponer oficialmente, a figuras internacionales como Pablo Picasso; aunque, en este caso, las gestiones realizadas por Orueta en septiembre de 1933, con el embajador Salvador de Madariaga, no tuvieron éxito, ante el desinterés por lo oficial español que venía mostrando su paisano malagueño ${ }^{20}$. Fue algo que, sin embargo, pronto cambiaría con el estallido de la guerra y los contactos con el maestro que, de un modo directo, retomaría Renau en $1936^{21}$. Igualmente, como refleja la correspondencia de Orueta, tampoco estuvieron exentas de pequeños desencuentros las respetuosas relaciones que, sin embargo, mantuvo con los críticos Manuel Abril, presidente de la Sociedad de Artistas Ibéricos, y Juan de la Encina, director del Museo de Arte Moderno. De manera que habría discrepancias, por ejemplo, con el primero a causa de la celebración de la referida exposición de París o las limitaciones para desarrollar en 1933 el programa de exposiciones veraniegas de la Sociedad, o, con el segundo, en los detalles de los diversos asuntos que trataron entre 1931 y 1933 sobre el Museo, su Patronato, sus reformas o sus propuestas de adquisición de obras (Pruna, Zuloaga, Nicanor Piñole, etc.) $)^{22}$.

con Ángel Establier, Secretario del Instituto Internacional de Cooperación Intelectual de la Sociedad de Naciones (Caja $1149-2,45,330-336)$.

18 La propuesta completa en las diferentes secciones de la DGBA fue, en Pintura: Pinazo, Rodríguez Acosta y Sunyer; en Escultura: Barral y Ferrant; en Arquitectura: Sánchez Arcas; en Grabado: Miguel Velasco; en Arte Decorativo: Juan José García y Carmen Baroja (Gaceta de Madrid, n. ${ }^{\circ} 119$, de 28-IV-1932, p. 725).

${ }_{19}$ Con fecha del 25-IV-1933 se estableció la fecha de la exposición y se designó por el MIPBA un comité compuesto por Ricardo de Orueta, como presidente; Ricardo Gutiérrez Abascal, Margarita Nelken, Luis Pérez Bueno, Manuel Abril, Miguel Martínez de la Riva, como vocales, y José Carreño España, como secretario (Gaceta de Madrid, n. ${ }^{\circ} 123$, de 3-V-1933, p. 810). Orueta confirmaría a Abril (carta de 26-VI-1933) que la exposición sería según su proyecto y el de De la Encina e hizo saber a André Dezarrois (carta de 28-VI-1933) los citados motivos del retraso (ACCHS, AT-Orueta, Cajas 1147-1, 5/18 y 1149-1, 5/035); pues, efectivamente, el ministro De los Ríos había sido sustituido por Francisco Barnés el 12-VI-1933, quien luego también lo confirmó en el cargo.

${ }^{20}$ El 15-IX-1933 se dirigía Orueta por telegrama al consejero de la Embajada de España en París, Aguinaga, preguntándole si Picasso se encontraba en su finca de Gisors o en París y sus teléfonos. Al día siguiente le respondía el embajador Madariaga, comentándole "la conducta incalificable de este señor para con el Representante oficial de España y un admirador de siempre de su pintura", pues desde que llegó no había perdido ocasión de invitarle a fiestas, almuerzos y cenas, sin conseguir que ni siquiera le contestase ni se pusiera al teléfono, por lo que le parecía "deplorable que hagan ustedes nada oficial con él, mientras no justifique su conducta”. Orueta contestó a Madariaga (20-IX-1933) comentándole el proyecto que tenía de celebrar una exposición-homenaje oficial sobre Picasso en Madrid, como las habían tenido Zuloaga y Anglada, aunque, añadía, "después de su carta queda totalmente desechado el proyecto, pues yo no puedo realizar nada que signifique un homenaje oficial a quien no guardó las más elementales normas de cortesía con el Representante oficial de su patria" (AGA, 10 (96), Caja 54/11038, Exp. 33-0769 y ACCHS, AT-Orueta, Caja 1152-1, 0134).

21 Véase Cabañas Bravo: Josep Renau..., op. cit., 2007, pp. 167-215 y Cabañas Bravo, M.: "Renau y el pabellón español de 1937 en París, con Picasso y sin Dalí”, en BrinuegA, J. (comisario): Josep Renau, 1907-1982. Compromís i Cultura, Valencia, Universitat de València-SECC, 2007, pp. 140-167.

22 Sobre estos asuntos en la correspondencia con Abril y Gutiérrez Abascal: ACCHS, AT-Orueta, respectivamente Caja 1147-1, 5/12-20 y Caja 1150-2, 810-837. 

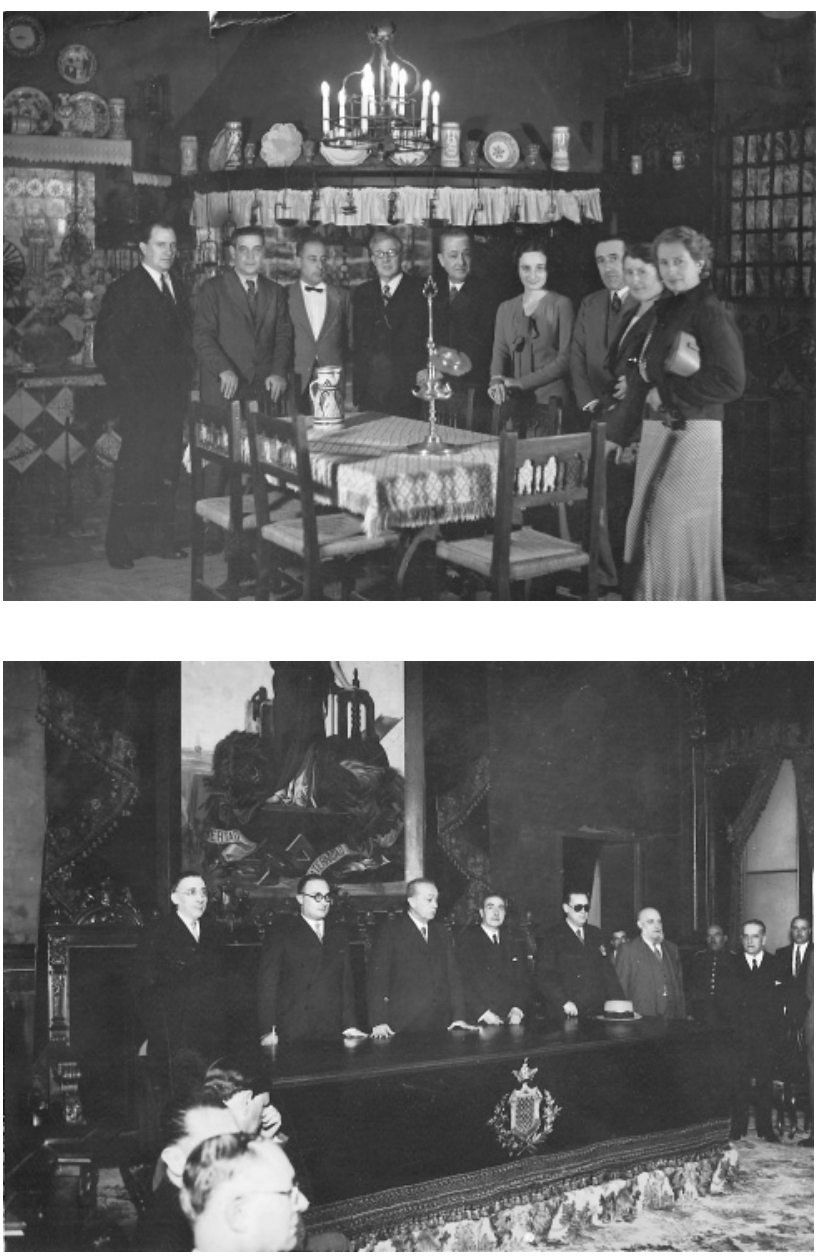

Fig. 3. Orueta (quinto) y su secretario José Carreño España (séptimo), junto a otras personalidades, en la cocina del recién creado Museu del Cau Ferrat de Sitges, durante su visita del 23-X-1933 (Archivo CCHS).

Fig. 4. Orueta (centro) y otras personalidades en el salón de actos del Ayuntamiento de Tarragona, durante el homenaje que le tributó éste el 22-X-1933 (Archivo CCHS).

Muy amplia fue, en otro orden, la labor en torno a la creación o reformulación de museos, su gestión y su acceso; de forma que, como ya vimos poner en marcha, continuaron las reformas apoyadas, fundamentalmente, en la citada creación de los nuevos Patronatos que los administrarían y en la regulación del acceso para ofrecer más facilidades a sus visitantes. Aunque a veces también se trató tanto del mantenimiento de unas estrechas relaciones con el Servei de Monuments Històrics de la Generalitat de Cataluña y con su Junta de Museus, como del impulso a innovadoras propuestas, diferentes a los museos tradicionales. En el primer caso, por ejemplo, podríamos recordar el respaldo al Museu del Cau Ferrat de Sitges, inaugurado el 16 de abril de 1933 con el legado de Santiago Rusiñol y al que Orueta giró una visita oficial, acompañado de varias personalidades, el 23 de octubre del mismo año (fig. 3). Ésta estuvo enmarcada en un amplio programa de reconocimientos similares a diferentes museos y monumentos catalanes entre los días 22 y 24 de ese mes, que también comprendió su significativa visita a las obras de restauración y creación de un museo en el Monasterio de Poblet y a diversas instalaciones de la ciudad de Tarragona; la visita en Barcelona al Museu de les Arts Decoratives de Pedralbes, a las obras de instalación del Museu d'Arqueologia y del Museu de l'Art de Catalunya en el Palau Nacional, a los archivos Històric de la Ciutat y de la Corona de Aragón y a la capilla de Santa Ágata, concluyendo su viaje con su entrevista oficial con el presidente catalán Francesc Macià 


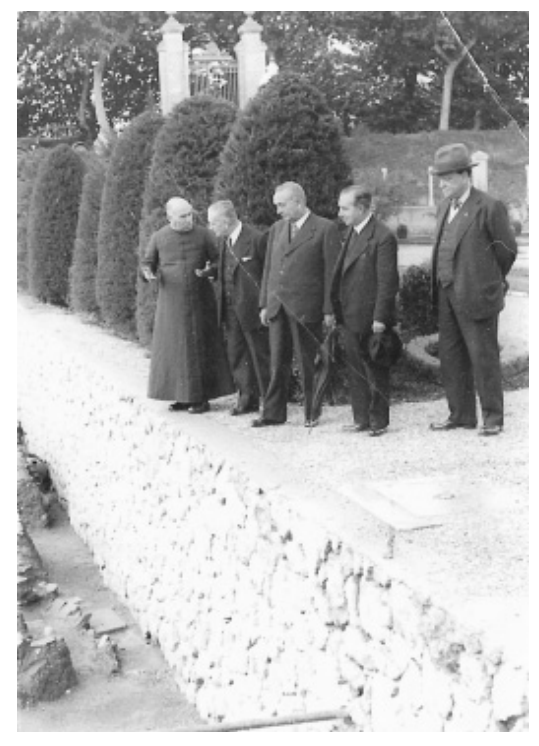

Fig. 5. Visita de Orueta (tercero) y otras personalidades el 22-X-1933, guiados por el erudito padre Joan Serra (primero), a la necrópolis paleocristiana de Tarragona, sita en la Fábrica de Tabacos (Archivo CCHS).

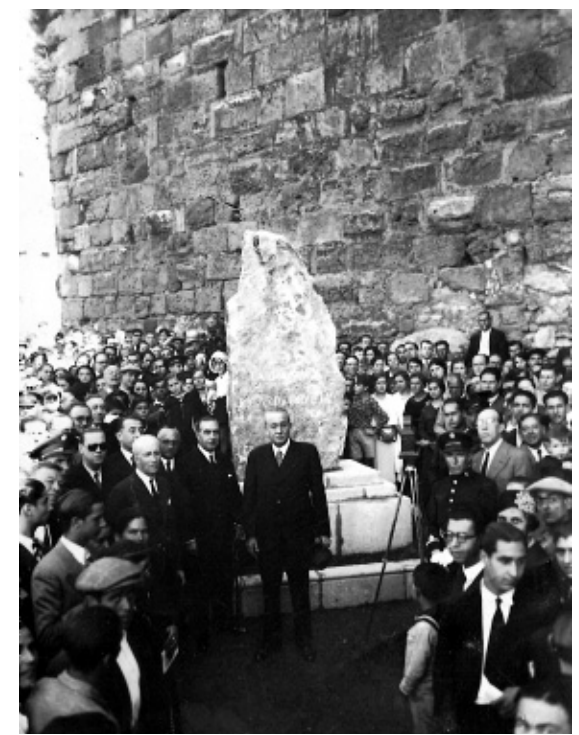

Fig. 6. Inauguración el 22-X-1933 del Paseo Arqueológico de Tarragona y del monumento-homenaje a Orueta que le dedicó la ciudad (Archivo CCHS).

y la visita a las excavaciones de Ampurias. Entre las renovadoras iniciativas del segundo caso, podríamos recordar, sin incluso salir del marco de esta visita catalana, la innovadora propuesta del Paseo Arqueológico de Tarragona formulada en 1932 por Jeroni Martorell, autor del proyecto y director del citado Servei, con objeto de poner en valor las murallas y fortificaciones tarraconeses, la cual se concluyó con su inauguración por Orueta el 22 de octubre de 1933. El proyecto del Paseo Arqueológico, vinculado a las excavaciones y descubrimiento de una necrópolis romana en la Fábrica de Tabacos y al museo de la ciudad, todo ello también visitado en aquella ocasión (fig. 5), fue una realización en la que Orueta puso especial empeño personal, lo que le correspondió Tarragona durante esa gira de 1933, dedicándole un gran homenaje y un monumento (figs. 4, 5 y 6), que aún persiste (fig. 9) 23 .

No obstante, entre otras iniciativas sobre los museos, durante este período ciertamente se creó el Museo de Aranjuez, para el que se partía del Patrimonio de la Corona (Decreto de 27-I-1932); se transformaron los museos Arqueológico de Barcelona en Museo Epigráfico (Decreto de 3-

23 Sobre las diferentes visitas y actuaciones en su gira catalana de octubre de 1933, en especial en su paso por Sitges y Tarragona, véase: "Los monumentos de Tarragona. Homenaje al director de Bellas Artes", La Vanguardia, Barcelona, 21-X-1933, p. 16; MARTORELL, Jeroni: "Valoració monumental i consolidació de les muralles de Tarragona" y "Els senyors Orueta i 'Juan del Encina' visiten els nostres museus", ambos en Butlletí dels Museus d'Art de Barcelona, n. ${ }^{\circ} 31$, vol. 3, Bacelona, diciembre de 1933, pp. 365-375 y 376-377. Por otro lado, entre la amplia correspondencia con Orueta que generaron las iniciativas comentadas, véase la mantenida en 1932 con Luis de Albacete, director general de Tabacalera en Tarragona (ACCHS, AT-Orueta, Caja 1147-1, 0130-0133), con la Academia de San Fernando a través de Manuel Zabala para la tramitación del expediente del proyecto del Paseo Arqueológico (Caja 1154-1, 331-338) o con el alcalde Pere Lloret, la prensa y otras personalidades de Tarragona (Caja 1153-3, 144-146, 0844-0980). 
III-1932) y Provincial de Soria en Museo Celtíbero (Decreto de 27-VI-1932); se compró la casa de Pérez Galdós en Santander con objeto de crear el Museo y Biblioteca Galdosianos (Ley de 8-X-1932); se refundieron otros dedicados a las armas y lo militar en el Museo Histórico Militar de Madrid (Decreto de 16-XII-1932); se creó el Museo Arqueológico Provincial de Almería (Decreto de 28-III-1933) y, sobre todo, puesto que fue una iniciativa muy personal del mismo Orueta, en la que también puso un gran tesón, se trasformó en abril de 1933 el viejo Museo Provincial de Valladolid en Museo Nacional de Escultura, dotándosele poco después de su Patronato (Decretos de 29-IV-1933 y 23-VII-1933). Sobre casi todas estas iniciativas -y aún otras menos conocidas o que no llegaron a consumarse-, ha quedado una interesante correspondencia de Orueta con alcaldes, gobernadores, delegados, directores, vocales de Patronatos, comisionados, coleccionistas, académicos, etc., de entre las que, a modo de ejemplo, podríamos señalar-por su continuidad y los elogios que tendría la iniciativa- la mantenida con Francisco de Cossío, el primer director del citado museo vallisoletano ${ }^{24}$, el cual ha perdurado como Museo Nacional hasta la actualidad.

Por otro lado, la Ley de 22-III-1932 trasformó la naturaleza jurídica de los bienes del Patrimonio de la Corona para darles destinos científicos, artísticos, sanitarios, docentes, sociales y turísticos, convirtiéndose muchos de ellos en museos y centros abiertos al turismo. Para su gestión, también se creó un Consejo de Administración, supervisado por el Ministerio de Hacienda, al que perteneció Orueta por méritos diferentes al de su cargo al frente de la DGBA, como se apresuró a rectificarle al crítico de arte Manuel Abril25; aunque, ciertamente, el malagueño fue uno de los principales protagonistas de las medidas y destinos que se dieron a los diferentes inmuebles, como pone de manifiesto su correspondencia con el ministro De los Ríos y el secretario de dicho Consejo, José Ignacio Aldama ${ }^{26}$.

Aunque sin lugar a dudas, si algo destaca de estos momentos, es la anunciada Ley de Protección del Tesoro Artístico Nacional de 13-V-1933, que ya se había comenzado a preparar en marzo de $1932^{27}$ y tuvo luego una lenta tramitación parlamentaria, hasta su publicación en la Gaceta de Madrid de 25-V-1933, retardándose también la publicación de su reglamento de aplicación hasta abril de 1936. Sin embargo, sería imposible exagerar su trascendencia si pensamos que se mantendría, sin grandes variaciones, hasta la transición democrática iniciada en 1977 y no sería derogada hasta 1985. El relator de la Ley fue Ricardo de Orueta, quien se asesoró con los mejores especialistas del momento. La Ley, que venía a dar desarrollo directo al citado artículo 45 de la Constitución, también vino a regular múltiples materias, entre ellas: el contenido y noción de "patrimonio histórico-artístico nacional", reservado a los inmuebles y objetos artísticos con más de un siglo de antigüedad; la organización administrativa para la defensa de estos bienes, fundamentalmente articulada en torno a la DGBA, apoyada por la Junta Superior del Tesoro

24 Véase ACCHS, AT-Orueta, Caja 1148-2, 183, 0897-0952. Entre los reconocimientos a Orueta por la iniciativa, valga la unánime felicitación de los académicos de San Fernando al inaugurar la Corporación sus sesiones del año 1933-1934 (que además le propondrían como vocal del Patronato), comunicada el 3-X-1933 por su secretario Manuel Zabala (Caja 1154-1, 320) o la de su maestro Elías Tormo (Caja 1153-3, 170, 1170).

${ }^{25}$ En su carta de 28-VI-1933, Orueta pedía a Abril que rectificara su artículo de 31-VII-1932 en Luz, haciendo constar que "el Director General de Bellas Artes no tiene jurisdicción ninguna sobre las obras de arte que constituyen el Patronato de la Corona" (dependientes del Ministerio de Gobernación), y le explicaba la división hecha entre bienes de Patronato y de Patrimonio, perteneciendo con un voto únicamente a la Junta que regía los segundos (ACCHS, ATOrueta, Cajas 1147-1, 5/20).

26 Véase sobre su correspondencia en esta materia con el ministro y Aldama, respectivamente: ACCHS, AT-Orueta, Cajas, 1152-2, 129/765 y 1147-1, 37/225-291.

27 El 25-III-1932 Orueta enviaba al ministro De los Ríos "el proyecto de ley de protección del Tesoro Artístico en papel escrito en el papel protocolario", indicándole que: "El prólogo brevísimo sólo expone los motivos legales de su presentación: si Vd. estima que debe ser más extenso exponiendo los otros motivos que justifican la Ley, podemos hacerlo después, pero se lo mandó como está para ganar tiempo" (ACCHS, AT-Orueta, Cajas, 1152-2, 129/755). 
Artístico con sus Delegaciones Locales y la Inspección General de Monumentos y varios organismos consultivos (Academias, Facultades, Escuelas Superiores, Patronatos de Museos, etc.); las atribuciones de la Dirección General de Seguridad ante las infracciones; el procedimiento de declaración monumental y el régimen jurídico de estos bienes protegidos y los casos de intervención administrativa; el régimen de los bienes muebles, intransferibles sin autorización cuando pertenecieran a las administraciones o a la Iglesia y con diferentes limitaciones para su exportación o venta; las medidas de tutela, inspección y fomento museístico y arqueológico o las reglas de formación de un inventario del patrimonio histórico-artístico nacional.

Hay que destacar sobre esta primera etapa de responsabilidad del malagueño, por tanto, que, pese al cambio de ministros titulares del MIPBA, en la DGBA hubo una gran continuidad de orientación y actuación, gracias a la confirmación y persistencia de Orueta al frente de la DGBA. Así, su papel gestor, informador e impulsor en la orientación reformadora y normativa que siguió el MIPBA en materia histórico-artística fue primordial y de singular trascendencia, dada la gran repercusión que la labor republicana de este período, en sí misma, estaba llamada a tener en la posterior actuación político-administrativa y legislativa del país. Pero, además de los perfiles reguladores y administrativos, el acento especial de esta gestión de Orueta realmente se volcó en la creación de estructuras de estudio, protección y promoción del arte, complementadas en su enfoque con la relevancia que otorgó a la documentación y catalogación de nuestro patrimonio artístico. Aunque, sin embargo, tampoco abandonaría plenamente la actividad, en varios de estos aspectos, cuando fuera apartado del cargo durante el bienio radical-cedista. Es decir, con la Ley de mayo de 1933, nació la Junta Superior del Tesoro Artístico Nacional, precisamente encargada del cumplimiento de las disposiciones de dicha norma y articulada en diferentes secciones y delegaciones locales, aunque ejecutivamente dependiente de la DGBA; y, sin que apenas hubiera trascurrido un mes desde que dejara la citada responsabilidad, por acuerdo unánime, el historiador malagueño fue nombrado presidente de la misma el 23 de enero de 1934, manteniéndose en este puesto hasta el 19 de junio de 1936, fecha en la que lo reemplazará Gómez Moreno ${ }^{28}$.

\section{El segundo periodo de Orueta al frente de la DGBA (febrero-septiembre 1936)}

Tras la descrita primera etapa de gestión al frente de la DGBA, a Orueta le sucedieron dos nuevos y más efímeros directores de este departamento ministerial, el pintor Eduardo Chicharro Agüera, entre diciembre de 1933 y marzo de 1935, y Antonio Dubois García, entre marzo y septiembre de $1935^{29}$. Este último director general alcanzó a ver lanzado el Decreto de 28-IX-1935,

28 El nombramiento de Orueta se dio por Decreto de 23-I-1934, a propuesta de la citada Junta y el MIPBA (Gaceta de Madrid, n. ${ }^{\circ}$ 26, de 26-I-1934, p. 652). Ya estando de nuevo al frente de la DGBA, el malagueño ofreció su dimisión como presidente de dicha Junta, aceptada por Decreto de 19-VI-1936, fecha también del Decreto de nombramiento de Manuel Gómez Moreno, que lo sustituía (ambos en Gaceta de Madrid, n. ${ }^{\circ} 173$, de 21-VI-1936, p. 2550). El SecretarioInterventor de esta Junta fue, a partir de mayo de 1936, José Carreño España, quien convocó a las diferentes reuniones de la Junta en 1936 (celebradas en el Museo Arqueológico Nacional el 17-VI; 4-VI y 6-VII) y levantó actas como la de 17-VI-1936, en la cual, entre los asuntos, se recoge la dimisión presentada por Orueta, "por estimar que el espíritu regulador de la ley creadora de la Junta hace incompatibles el cargo de Presidente, con el de Director General de Bellas Artes", y la elección de Gómez Moreno, que aceptaba haciendo constar que sólo atendería a criterios profesionales y no políticos (ACCHS, AT-Orueta, Caja 1154, carpeta C-1936).

${ }_{29}$ El nombramiento de Chicharro se produjo al ocupar la cartera del MIPBA José Pareja Yévenes (Decreto de 26XII-1933, Gaceta de Madrid, n. ${ }^{\circ}$ 361, de 27-XII-1933, pp. 2172-2173), manteniéndose con sus sucesores en la cartera: Salvador de Madariaga, Alejandro Lerroux, José María Cid, Filiberto Villalobos y Joaquín Dualde, a quien presentó su renuncia el 12-III-1935 (Gaceta de Madrid, n. ${ }^{\circ}$ 73, de 14-III-1935, p. 2115). A propuesta de este último ministro se nombró director general a Antonio Dubois el 23-III-1935 (Gaceta de Madrid, n. ${ }^{\circ}$ 85, de 26-III-1935, p. 2381), quien 
por el cual, el Gobierno radical-cedista encabezado por Joaquín Chapapietra, suprimía la DGBA. Aunque cinco meses más tarde, tras la victoria del Frente Popular y con Manuel Azaña nuevamente en la Presidencia del Consejo, el reciente Gobierno, haciéndose eco del malestar creado y volviendo a la línea de trabajo emprendida en el bienio reformista, por Decreto del MIPBA de 24-II-1936, restablecía este departamento ministerial.

El mismo preámbulo de tal Decreto, firmado por Alcalá-Zamora a propuesta del titular del MIPBA, Marcelino Domingo, ya indicaba cómo, ante la supresión en septiembre de la DGBA, "se alzaron en contra de la medida adoptada voces autorizadas de sectores diversos y aun opuestos", considerando el actual Gobierno que, las Bellas Artes, no podían ser "un cúmulo de asuntos administrativos, sino un tema de constante atención". Para ello se necesitaba un "órgano de iniciativa y realización", que sirviera de enlace con otros cuerpos técnicos y asesores del Estado y que buscara la máxima eficacia tanto en la conservación y conocimiento "de los tesoros artísticos del pasado español", como en el estímulo y divulgación - dentro y fuera de España- "del arte actual" y el fomento de "futuros cultivadores". El Decreto, además, terminaba esbozando así un plan gubernamental, que enlazaba con sus actuaciones anteriores:

"Para ello [el Gobierno] no tiene más que continuar la labor emprendida de 1931 a 1933: desarrollar lo dispuesto por la ley de Protección al Tesoro artístico; seguir lo iniciado por los Gobiernos del primer bienio de la República con los Museos de Valladolid, Toledo, Arte Moderno, Arqueológico Nacional, etcétera; preocuparse de la mejora de las enseñanzas artísticas; de la organización de Concursos y Exposiciones; de la construcción y adorno de los edificios públicos; del acondicionamiento y catalogación de Archivos y Bibliotecas; de la protección a las manifestaciones musicales; de la depuración artística del Teatro y de su difusión, especialmente del clásico; etcétera, etc. El índice es tan vasto que con razón, aunque tantas veces se haya echado en olvido, "Bellas Artes" es la mitad del nombre del Ministerio, y no parece concepto excesivo cuando se piensa en lo que significa fuera de España el valor de su Arte antiguo y de su Arte actual"30.

En la misma fecha que el flamante Gobierno restablecía la DGBA, de nuevo volvía a poner al frente de dicho departamento a Ricardo de Orueta, quien permaneció en el cargo hasta que, con el Gobierno de Largo Caballero, presentó su dimisión al ministro comunista Jesús Hernández en septiembre de $1936^{31}$. Lógicamente, la línea de actuación del historiador malagueño en esta segunda etapa, como quería el Gobierno, sería de continuidad con su actuación anterior. De manera que, entre otras medidas, Orueta asumirá la Jefatura de las Exposiciones Nacionales de Bellas Artes (Decreto de 4-III-1936), recuperando ese control para su departamento o, yendo a nuevas actuaciones, se haría presente como vocal en la comisión mixta creada para formar el inventario de los bienes, derechos y adaptación de los servicios cedidos por el Estado a la Autonomía de Cataluña o de nuevo regresaría a Sitges el 14 de junio para inaugurar, junto al presidente de la Generalitat, el Museo Ma-

mantuvo el puesto con los ministros Ramón Prieto Bancés y Joaquín Dualde, hasta que Juan José Rocha lo cesó el 30-IX-1935, en cumplimiento del Decreto de 28-IX-1935 del Ministerio de Hacienda, que ejecutaba la Ley de 1-VIII1935 reorganizando los servicios centrales de la Administración del Estado, lo que suponía la desaparición de la DGBA. (Decreto de cese retrospectivo del director de 18-X-1935, Gaceta de Madrid, n. ${ }^{\circ} 285$, de 11-X-1935, p. 223.)

30 Decreto del MIPBA de 24-II-1936 (Gaceta de Madrid, n. ${ }^{\circ}$ 56, de 25-II-1936, p. 1597).

31 El Decreto de su nuevo nombramiento, a propuesta del ministro Marcelino Domingo, es de 24-II-1936 (Gaceta de Madrid, n. ${ }^{\circ}$ 56, de 25-II-1936, p. 1597). Continuó también en el cargo con el ministro Francisco Barnés, durante el Gobierno de José Giral, y le fue aceptada su dimisión con Jesús Hernández por Decreto de 9-IX-1936 (Gaceta de Madrid, n. ${ }^{\circ}$ 254, de 10-IX-1936, p. 1730). 
ricel y la exposición temporal sobre El Greco que éste acogería ${ }^{32}$. Pero, sobre todo, en este segundo acceso al cargo, como pronto veremos, Orueta fue quien tuvo que hacer frente más directamente a las primeras medidas de protección del patrimonio tras el estallido de la guerra; para lo que no tardó en servirse de su experiencia previa en el puesto. Fue un período de responsabilidad, por tanto, más breve, pero especialmente intenso y decisivo ante los excesos del conflicto y las urgentes medidas tomadas; del cual sobresaldría, además del inicio de la depuración del personal desafecto y la adaptación a la situación bélica de las estructuras, la creación -apenas cinco días después de producida la sublevación- de lo que será la Junta de Incautación y Protección del Tesoro Artístico.

Sin embargo, su gestión no comenzó por aquí, ni su vuelta fue recibida sin reservas por algunos sectores avanzados. Así, por ejemplo, el intuitivo y polifacético creador Gabriel García Maroto, que había criticado mucho los anteriores vaivenes ministeriales respecto a las Bellas Artes, continuó ofreciendo desde el diario socialista madrileño Claridad -a cuyo comité de redacción pertenecía desde sus inicios con Álvarez del Vayo, Luis Araquistáin, Carrillo, Antonio Machado, Margarita Nelken, Robledano y otros- soluciones dirigidas a los desatendidos artistas contemporáneos. Propondría ahora, pues, el desvío de los recursos asignados a la Exposición Nacional para decorar con frescos los nuevos grupos escolares o el incentivar a los artistas, desmotivados con el régimen por su falta de una misión concreta de tipo social ${ }^{33}$; aunque, sobre todo, como haría en un artículo aparecido el 3 de junio, el manchego criticaría lo poco que había cambiado la gestión republicana, que continuaba con su "tono prudente, arqueológico", y la necesidad de crear una fresca y dinámica DGBA, con una eficiente dirección de tono actualizado, reformadora y preocupada por los actuales artistas avanzados en sus diferentes disciplinas y aprendizaje ${ }^{34}$. Pero, al mismo tiempo, hubo otros periodistas correligionarios, como Emiliano Aguilera, de El Socialista, que, aunque al inicio de la gestión del malagueño, lamentaron "su benevolencia para los que pretenden mantener en la República la influencia que hubieron de ejercer durante la Monarquía", se distanciaron luego de ciertas opiniones del periódico adversas a la DGBA y propusieron soluciones para centros como la Escuela Nacional de Artes Gráficas ${ }^{35}$.

Toda la escena artística progresista, en realidad, parecía motivada y creía llegado el momento de introducir importantes cambios, tras el bienio de gobiernos de derechas; pero con el nombramiento de Orueta sólo se percibió la continuidad de unas reformas moderadas. Éste comenzó intentado estimular a los más destacados especialistas españoles en Historia del Arte, para hacerlos presentes en importantes foros internacionales, como el XIV Congreso Internacional de Historia del Arte, previsto celebrar en septiembre de 1936 en Basilea (Suiza). Para esta cita, ya en marzo de ese año, nombró una delegación española compuesta por Gómez Moreno (su presi-

32 Tras la aprobación de un nuevo reglamento de las citadas Exposiciones Nacionales y el restablecimiento de la DGBA (Decretos de 6-II-1936 y 24-II-1936), las atribuciones conferidas al subsecretario del MIPBA fueron transferidas al director general de Bellas Artes, que asumía la Jefatura de las Exposiciones (Decreto de 4-III-1936, Gaceta de Madrid, n. ${ }^{\circ}$ 65, de 5-III-1936, p. 1846). La Orden de Presidencia del Consejo de 31-V-1936, designaba a Orueta como vocal suplente para formar parte de la citada Comisión mixta (Gaceta de Madrid, n. ${ }^{\circ} 157$, de 5-VI-1936, p. 2046). Sobre su nueva presencia en Sitges, véase: "El nuevo Museo Maricel", La Vanguardia, Barcelona, 13-VI-1936, p. 8.

33 Véase, respectivamente, García Maroto, G.: "Cuadros y muros. La Exposición Nacional de Bellas Artes y los nuevos grupos escolares", Claridad, n. ${ }^{\circ}$ 27, Madrid, 27-V-1936, p. 7 y "El arte y el pueblo. En la agonía de un régimen. A qué sirven, de qué viven y qué es lo que esperan los pintores y escultores de España”, Claridad, Madrid, 8-VI-1936, p. 6. Sobre el socialista García Maroto, Claridad y estos artículos, véase SERRANO DE LA CruZ, Angelina: Las artes plásticas en Castilla-La Mancha: de la Restauración a la II República, Toledo, Junta de Comunidades de Castilla-La Mancha, 1999, pp. 394-396.

${ }^{34}$ García Maroto, G.: "El arte y el pueblo. Arqueología y arte de hoy”, Claridad, Madrid, 3-VI-1936, p. 6. Véase también sobre estos planteamientos CABAÑAS BRAVo: Josep Renau..., op. cit., 2007, pp. 35-40.

35 Véase la carta de éste a Orueta de 20-III-1936, acompañada de su artículo "Más sobre la Escuela Nacional de Artes Gráficas”, El Socialista, 19-III-1936 (ACCHS, AT-Orueta, Caja 1154, carpeta A-1936). 
dente), José Ferrandis, Sánchez Cantón, Torres Balbás, Camón Aznar, López Otero y José López $R_{e y}{ }^{36}$. Igualmente, entre esas primeras actuaciones, estuvo preocupado por la reorganización de las Escuelas de Artes y Oficios y el nombramiento de un inspector definitivo de confianza, como le manifestaba en abril al presidente Manuel Azaña ${ }^{37}$; asimismo llamó la atención a Santiago Casares Quiroga - tanto en su etapa de ministro de Obras Públicas como en la de presidente del Consejo- para prevenir incidentes, dar protección o reconstruir monumentos y espacios museísticos, como el Monasterio de Guadalupe, el Museo de Pintura y el Convento de San Francisco de Cádiz o la Cámara Santa de Oviedo ${ }^{38}$; o, en fin, puso una gran confianza en el regreso de Cipriano Rivas Cherif de sus giras, para -como le dirá en junio- "que continúes aquí la campaña de dignificación artística del arte teatral que habéis emprendido [con Margarita Xirgú] y para la cual ya sabes que cuentas con esta Dirección mientras yo esté aquí" 39 .

Con todo, serían muy pocas las medidas de cierto alcance que la DGBA, embarcada en su propia reconstrucción, pudo llevar a cabo en el breve período anterior a la guerra. Aunque, no obstante, entre las diferentes normativas aparecidas y las actuaciones promovidas, podría destacarse la Resolución de 16-IV-1936 del director general de Bellas Artes, concediendo acceso gratuito a los Museos y Monumentos nacionales a los periodistas españoles, que fue ampliada con la Resolución de 24-IV-1936, que reguló los modelos de pase de favor. O, en otros aspectos museísticos, asimismo hay que recordar, por ejemplo, la creación del Museo de Armas y Tapices (Decreto de 5-V-1936), a partir de los bienes de Patrimonio de la República; actuación a la que precedieron la remodelación museográfica -según proyecto de Luis Moya- de las Salas Americanas y Egipcias del Museo Arqueológico (Orden del MIPBA de 11-III-1936), la reparación -según proyecto de Pedro Muguruza- del Museo del Prado (Orden de 27-IV-1936) o, fuera de Madrid, las obras de conservación y mejora -según proyecto de Antonio García Sánchez Blanco- del Museo Provincial de Bellas Artes de Zamora (Orden de 10-IV-1936).

Hay que volver a evocar también el importante Decreto de 16-IV-1936, por el que se aprobaba el Reglamento para la aplicación de la Ley del Tesoro Artístico Nacional de 1933, el cual regularía la Junta Superior del Tesoro Artístico y sus Juntas Delegadas, los monumentos histórico-artísticos, las excavaciones arqueológicas, los objetos muebles, los Museos, y el inventario del Patrimonio Artístico y la difusión de la cultura artística. Igualmente se dieron entonces la Orden del MIPBA de 3-VI-1936, por la que el territorio nacional se dividió en una serie de zonas, en las que desarrollarían su quehacer los Arquitectos Conservadores de Museos, y varios decretos más con declaraciones de monumentos histórico-artísticos, como, en Málaga, las ruinas romanas de Torre de las Bóvedas en San Pedro de Alcántara (Decreto de 6-IV-1936) o, en Navarra, el castillo-basílica de Santa María la Real Ujué (Decreto de 26-VI-1936). Al mismo tiempo que, por aquellas fechas, se dieron muchas otras órdenes sobre rehabilitación de edificios histórico-monumentales, a propuesta de la Junta Superior del Tesoro Artístico: Capilla de San Miguel en la Seo de Zaragoza, Iglesia de Villalpando (Zamora), Archivo de Simancas, Colegiata de Játiva (Valencia), la Torre de San Martín (Teruel), Hospital de Santa Cruz en Toledo, Iglesia del Cristo de la Vega en Toledo, palacio y jardines del Generalife en Granada, etc. Sin embargo, el plan más ambicioso que promovió ahora la DGBA fue el que dio lugar a la Ley de 5-VI-1936 sobre la conservación de monumentos singulares, la cual contemplaba excavaciones y adquisición de edificios y terrenos con destino

\footnotetext{
${ }^{36}$ Véase, tras la invitación oficial del embajador suizo en febrero, la resolución de la DGBA y su traslado a los interesados, que firmará Orueta el 21-III-1936 (ACCHS, AT-Orueta, Carpeta R-1936, Relaciones Culturales).

${ }^{37}$ Carta a M. Azaña de 25-IV-1936 (ACCHS, AT-Orueta, Carpeta A-1936).

38 Véase la correspondencia entre ambos de abril a julio de 1936 (ACCHS, AT-Orueta, Carpeta C-1936).

39 En su carta de 5-VI-1936, Orueta también le indicaba que esperaba su regreso para que asumiera el cargo de Delegado del Teatro María Guerrero y le aseguraba que "el T.E.A. sigue y seguirá en su teatro y allí puede realizar toda su labor" (ACCHS, AT-Orueta, Carpeta R-1936).
} 


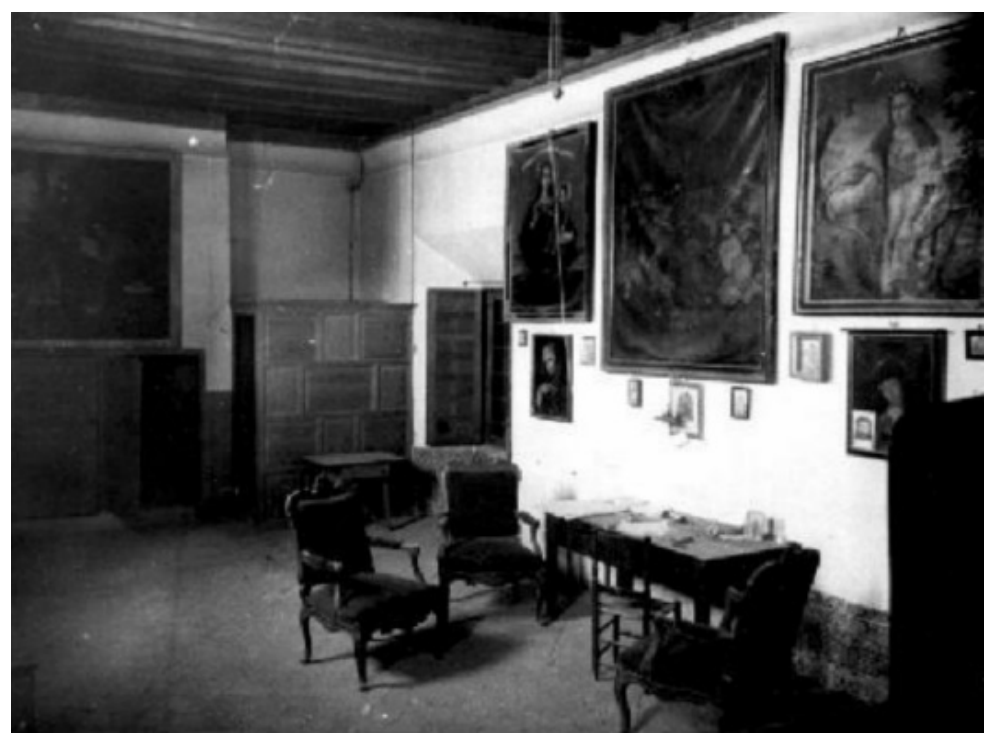

Fig. 7. Sala de trabajo en el convento de las Descalzas Reales de Madrid, que fuera la primera sede de la Junta de Incautación y Protección del Tesoro Artístico creada el 23-VII-1936 (Foto: Atienza, VII-1936, AGA).

al Tesoro Artístico, por valor de casi siete millones de pesetas, y proponía intervenciones en 31 monumentos, si bien el golpe militar del 18 de julio de 1936 truncaría el plan.

A Orueta, la sublevación le pilló en Sevilla, aunque muy poco después estaba ya en Madrid ${ }^{40}$. Y sería muy duro con los compañeros y subordinados que habían abandonado el trabajo, como Francisco Abbad, del Fichero de Arte Antiguo del CEH. Éste se había ido sin consultarle, aunque de haberlo hecho -como le dirá el malagueño- "le hubiera aconsejado, dados los acontecimientos que ya comenzaban a entreverse y el antecedente de su antigua inscripción política, que no se marchara por el momento", viéndose ahora precisado a dar orden de retenerle la paga en el CEH y recomendarle que, cuando volviera, "se traiga un certificado del Frente Popular de esa [localidad], para que pueda recibirle otra vez en el Fichero"41.

Su labor ahora, en el inicio del conflicto, sería especialmente trascendente en cuanto a las medidas tomadas para la protección del patrimonio histórico-artístico. Pero no vamos a entrar a exponer aquí con excesivo detalle la compleja trama y desarrollo de la citada Junta de Incautación y Protección del Tesoro Artístico y otras creadas en paralelo, como tampoco podemos detenernos en todas las actuaciones de la gestión general del patrimonio artístico-cultural en el ámbito republicano, temas suficientemente analizados para nuestro propósito por diferentes profesionales ${ }^{42}$. Sólo destacaremos ahora algunos aspectos pioneros en el momento bélico; y digamos, en este sentido, que el nacimiento y puesta en marcha de la inicial Junta de Incautación y Protección del Tesoro Artístico (fig. 7), aunque luego la desarrollaría mucho más su sucesor en el cargo, Josep

${ }^{40}$ Lo comenta en su carta de 20-VIII-1936, con la que respondía a la de Francisco Abbad de 19-VII-1936 (ACCHS, AT-Orueta, Caja 1154, carpeta A-1936).

${ }^{41}$ Carta de 20-VIII-1936 a Abbad, que respondía a la de éste de 19-VII-1936 desde Benabarre (Huesca). Ibidem.

${ }^{42}$ Son de especial interés, para el período tratado aquí, el estudio de Álvarez Lopera, José: La política de bienes culturales del Gobierno Republicano durante la Guerra Civil Española, Madrid, Ministerio de Cultura, 1982, 2 vols., y los trabajos recogidos en el catálogo: Argerich, Isabel, y ArA, Judith (ed.): Arte protegido. Memoria de la Junta del Tesoro Artístico durante la Guerra Civil, Madrid, IPHE-M. N. del Prado (Exposición MNP, VI/IX-2003), 2003. 
Renau, en realidad se debió al experimentado historiador malagueño, que había vuelto a ponerse al frente de la DGBA apenas hacía seis meses.

Fue Orueta, pues, quien, ante el estallido de la guerra, el posicionamiento, la desorganización y el peligro para el patrimonio que supuso la incontrolada quema de edificios religiosos e incautación de residencias aristocráticas, inició en la DGBA la depuración del personal desafecto a la República y adaptó sus estructuras a las nuevas condiciones, promoviendo la creación en Madrid, por Decreto del MIPBA de 23 de julio, con carácter de emergencia y sin más rótulo, una primera Junta para defensa del patrimonio compuesta por aliancistas ${ }^{43}$. Pero, al demostrar la práctica su insuficiencia, a la semana, el nuevo Decreto del MIPBA de 1 de agosto, que la denominaría ya Junta de Incautación y Protección del Tesoro Artístico (JIPTA), ampliaría sus miembros y definiría mejor sus cargos, ofreciendo también mayor precisión sobre las funciones de incautación y conservación realizables en nombre del Estado y asignándola recursos para su funcionamiento ${ }^{44}$. Ello pronto permitió a esta herramienta de protección del patrimonio artístico, histórico y bibliográfico, dotarse de una infraestructura, una normativa de actuación y una serie de grupos de trabajo que, organizados en comisiones, comenzaron una tímida actuación.

Este último Decreto, por otro lado, en buena medida también venía a ratificar y fortalecer mucha de la experiencia acumulada por la DGBA en la actividad que, aceleradamente, impulsó durante la semana trascurrida entre ambas disposiciones definidoras de la Junta. Orueta, ciertamente, en esa última semana del mes de julio, había procedido con rapidez e intentando ser sumamente escrupuloso y claro con la legalidad, con el personal autorizado a intervenir y con los depósitos de las obras en toda la actuación emprendida por la DGBA. De esta manera, buscó el respaldo del director general de Seguridad, a quien, el 25 de julio, informó del Decreto de dos días antes sobre la creación de la Junta y los miembros que la componían; al tiempo que le solicitó que les expidiera "el documento de identidad necesario a fin de que encuentren toda clase de facilidades en el desempaño de la misión que se les ha confiado, así como en lo que se refiera a transportes y vigilancia" ${ }^{95}$. Y, el 28 de julio, volvía a dirigirse a él comunicándole

43 El Decreto, en su artículo primero, constituía una Junta que había de estar "en relación inmediata con el Director general de Bellas Artes" y que la integrarían Ricardo Gutiérrez Abascal, Manuel Sánchez Arcas, Luis Quintanilla, Arturo Serrano Plaja, Carlos Montilla Escudero, Emiliano Barral y José Bergamín, y, en el segundo, la capacitaba para intervenir "con amplias facultades cuantos objetos de arte o históricos y científicos se encuentren en los palacios ocupados, adoptando aquellas medidas que considere necesarias a su mejor conservación e instalación y trasladándolas provisionalmente, si así lo estimare, a los Museos, Archivos o Bibliotecas del Estado" (Decreto del MIPBA de 23-VII-1936, Gaceta de Madrid, n. ${ }^{\circ}$ 207, de 25-VII-1936, p. 834). Los siete componentes de dicha Junta eran miembros de la Alianza de Intelectuales Antifascistas, organización de la que-según M. ${ }^{a}$ Teresa León, que incluso señala como impulsor a José Bergamín- partió la idea de su creación (La historia tiene la palabra, Madrid, Hispamerca, 1977, p. 32. Véase también Álvarez Lopera, Op. cit., 1982, vol. 1, p. 24 y "La Junta del Tesoro Artístico de Madrid y la protección del patrimonio en la Guerra Civil", en Argerich/Ara (ed.): Op. cit., 2003, pp. 29-30).

44 El preámbulo del Decreto ya indicaba:"la práctica ha demostrado prontamente que el número de los miembros de dicha Junta [del 23 de julio] es escaso en demasía, así como que las normas fijadas en el decreto de creación son insuficientes, en buena parte, a causa de limitarse la función de la Junta a los palacios ocupados, con lo que quedan fuera de su misión protectora las obras de valor que se albergan en iglesias, conventos y otros edificios". Por ello, ahora se ampliaban en cinco los vocales de la primera Junta, cuatro designados por el MIPBA y otro que sería el secretario técnico para la Política Artística de éste, José López-Rey. Además se facultaba a la Junta para nombrar Auxiliares, en quienes delegar funciones, y se la capacitaba para proceder "a la incautación o conservación, en nombre del Estado, de todas las obras, muebles o inmuebles, de interés artístico, histórico o bibliográfico, que en razón de las anormales circunstancias presentes ofrezcan, a su juicio, peligro de ruina, perdida o deterioro"; realizando la Junta estas incautaciones con carácter provisional, debiendo ser confirmadas, para que tengan carácter definitivo, por Decreto acordado en el Consejo de Ministros". (Decreto del MIPBA de 1-VIII-1936, Gaceta de Madrid, n. ${ }^{\circ} 215$, de 2-VIII-1936, p. 999).

${ }^{45}$ Minuta del oficio dirigido por el director general de Bellas Artes al director general de Seguridad, fechada: Madrid, 25-VII-1936 (AGA, Sección Educación, 5, Caja 31/6078, Exp. 14089-9). 


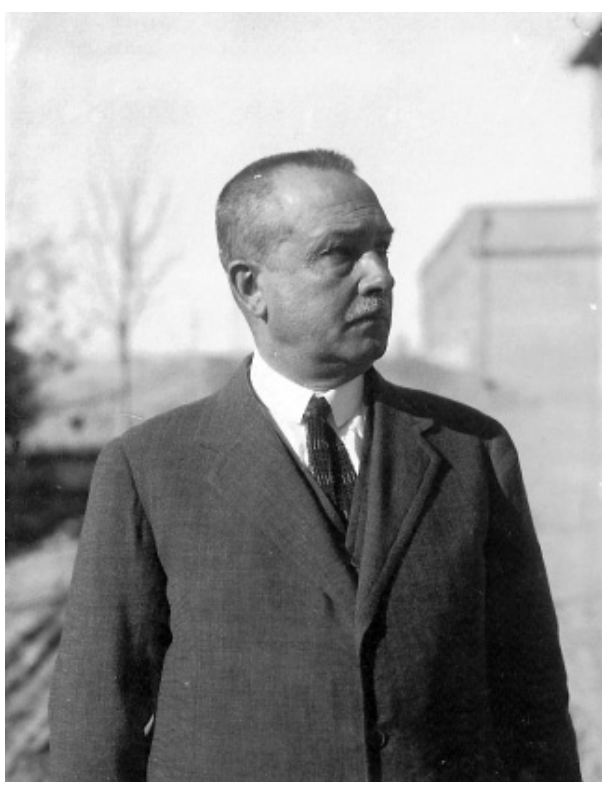

Fig. 8. Ricardo de Orueta en la Residencia de Estudiantes; años 30 (Archivo CCHS).

la base de su actuación, contenida en los artículos $1 .^{\circ}$ y $3 .^{\circ}$ del referido Decreto del MIPBA de 27-V-1931. Éstos autorizaban a la DGBA a intervenir cuando las obras de arte corrieran peligro, trasladándolas con objeto de preservarlas y cuidarlas a los museos provinciales o nacionales, siendo la autoridad encargada de efectuar la incautación el Gobernador Civil de la Provincia o el Director de Seguridad en la de Madrid (acompañados de la asesoría de un delegado de Bellas Artes), quienes, no obstante, podían delegar su autoridad ${ }^{46}$. Por ello, Orueta no sólo le transcribía junto a su misiva los citados artículos, sino que también le indicaba que, en vista de las "actuales circunstancias y el grave peligro que corren las obras de arte y riqueza artística en general", de conformidad con tales preceptos, la DGBA había resuelto "disponer el traslado de todas las obras que se hallen en el peligro de perderse o deteriorarse por falta de la debida custodia o el estado del edificio, al Museo Nacional del Prado a cuyo efecto se designa a los Arquitectos de Zona de

46 Este Decreto, que, como se recordaba en su preámbulo, complementaba al del MIPBA de 22-V-1931, dictado en defensa del Patrimonio Artístico Nacional y reconociendo el derecho de todos los españoles a su disfrute y la obligación de defenderlo que tenía el Gobierno, había sido inspirado, como el anterior, por la DGBA en tiempos del anterior período de responsabilidad del mismo Orueta. El artículo 1. ${ }^{\circ}$ del nuevo Decreto decía: "Cuando la Dirección General de Bellas Artes tenga conocimiento de que alguna obra artística se halla en peligro de perderse o deteriorarse por falta de la debida custodia, podrá disponer el traslado de la misma al Museo provincial, y si este no se hallase debidamente organizado, a uno de los Museos nacionales./ El depósito en estos Centros se entenderá hecho con carácter temporal, y antes de retirar las obras de arte de donde se hallaren, la autoridad encargada de hacerlo extenderá acta por triplicado en que conste por qué se adopta esta determinación, el reconocimiento del derecho a ser reintegradas a donde se hallaban cuando cesen las circunstancias que aconsejan aquella, y la descripción detallada de las obras de que se trate. De las tres actas referidas, una se entregará al Jefe de la entidad donde las obras se hallen; otra a la autoridad del Centro en que se depositen, y la tercera se enviará a la Dirección General de Bellas Artes para su archivo en la Sección del Tesoro Artístico Nacional". El artículo 3..$^{\circ}$ decía: "La autoridad encargada de efectuar la incautación temporal será el Gobernador civil de la provincia o el Director de Seguridad en la de Madrid, los cuales podrán delegarla, procurando, siempre que la urgencia del caso no lo impida, que intervenga en la misma el Delegado de Bellas Artes, como especializado en la materia. A cargo de éste estará la descripción de los objetos en el acta y las medidas precautorias para que no sufran deterioro en el traslado las obras de que se trate". (Decreto del MIPBA de 27-V-1931, Gaceta de Madrid, n. ${ }^{\circ}$ 148, de 28-V-1931, p. 976). 


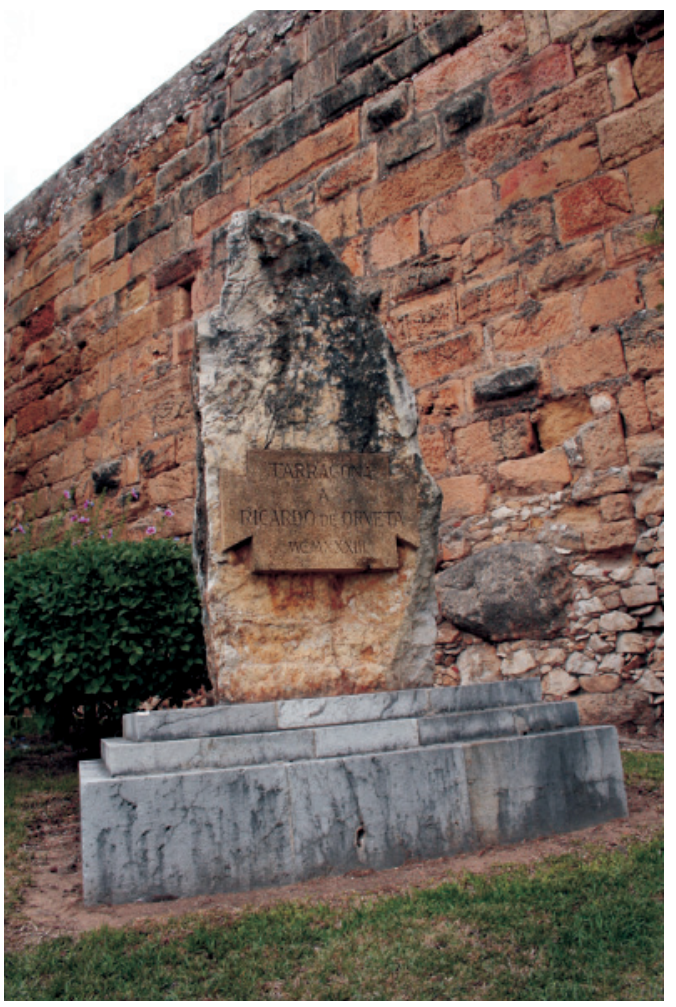

Fig. 9. Monumento de homenaje a Ricardo de Orueta junto a las murallas romanas de Tarragona, en la actualidad (Foto: M. Cabañas, 2006).

la Junta Superior del Tesoro Artístico, D. José Rodríguez Cano y D. Alejandro Ferrant, rogando a V. E. acepte tales nombres y delegue su autoridad al efecto de proceder a la incautación temporal de las joyas de arte que así se estimen y ordene se le den todas las facilidades y preste toda clase de auxilios tanto de vigilancia como de transporte para que puedan llevar a efecto su cometido con la rapidez que las circunstancias aconsejan"; demandas a las que, el citado director general de Seguridad, respondería positivamente ${ }^{47}$.

Igualmente, en esos mismos días que mediaron entre las disposiciones del 23 de julio y el 1 de agosto, el historiador malagueño procedió a recordar a los vocales de la Junta recién creada su facultad "para nombrar aquellos auxiliares que estime pertinentes", haciendo efectivas sus propuestas el 3 de agosto con varios nombramientos ${ }^{48}$. Al mismo tiempo, Orueta y sus colabora-

47 Oficio dirigido por el director general de Bellas Artes al director general de Seguridad, fechado: Madrid, 28-VII1936, que adjuntan la trascripción de los artículos $1 .^{\circ}$ y $3 .^{\circ}$ del Decreto de 27-V-1931, y contestación de este último, en el mismo día 28-V-1936, aceptando y delegando su autoridad en los citados arquitectos Rodríguez Cano y Ferrant, a quienes "les serán prestados cuantos auxilios estimen necesarios". (AGA, Sección Educación, 5, Caja 31/6078, Exp. 14089-9).

${ }^{48}$ La solicitud de propuestas la hacía Orueta el 27-VII-1936 (minuta y trasladados a cada uno de los miembros de la Junta. AGA, Educación, 5, Caja 31/6078, Exp. 14089-9). El oficio de 3-VIII-1936 dirigido por Orueta al presidente de la Junta Facultativa de Archivos, Bibliotecas y Museos, le informaba de que, a propuesta de la JIPTA, se había nombrado Auxiliares de la misma a los funcionarios adscritos a ese Cuerpo: Consuelo Vaca González, destinada en el Archivo del Ministerio de Obras Públicas; Matilde López Serrano, destinada en el Archivo del Palacio Nacional; Luis Vázquez de Parga, destinado en el Museo Arqueológico Nacional, Federico Navarro Franco, destinado en el Archivo Histórico Nacional, y Carmen Caamaño Díaz, destinada en la Biblioteca Nacional, a quienes se relevaba de cualquier 
dores, comenzaron a girar visitas a diferentes iglesias y conventos de Madrid (Catedral, Descalzas, Encarnación, San Andrés, Santiago, Caballero de Gracia, San Ginés, San Antón-Escolapios, Santa Bárbara, Maravillas, Capuchinas, San Plácido, Olivar-Dominicos y San Antonio de los Portugueses), terminando por redactar un breve informe sobre lo que en cada edificio procedía pasar a custodiar o transportar; solicitando también a los responsables eclesiásticos, cuando era preciso, que se facilitara la labor ${ }^{49}$.

Además, rápidamente, también se actuaría en torno al patrimonio bibliográfico y documental, para lo que fue clave la figura de Tomás Navarro Tomás, a la sazón Secretario de la JAE y director de la Biblioteca del CEH, institución de la que también procedía Orueta. Así, a propuesta del MIPBA, el Decreto de 5-VIII-1936, procedió a cesar en sus funciones a la Junta Facultativa del Cuerpo de Archiveros, Bibliotecarios y Arqueólogos y a su Consejo Asesor Consultivo, siguiendo el sentir de las dos últimas asambleas celebradas por los funcionarios del colectivo, y a nombrar para regir sus asuntos a una Comisión Gestora, presidida por Navarro Tomás e integrada por varios vocales de dicho Cuerpo, la cual debía proponer al Ministerio en breve plazo un plan de reorganización ${ }^{50}$. Esta Comisión Gestora estuvo siempre en estrecho contacto con la JIPTA, con la que mantuvo cierta relación de dependencia, informando puntualmente a su presidente (que primero fue Orueta y después Renau) de su diferente actividad en materia de incautaciones. El historiador malagueño, que sería reacio a las actuaciones que no provinieran de los cauces oficiales instituidos $^{51}$, completaba así la estructura armada desde la DGBA para el control y la

otro servicio que no fueran los encomendados por la JIPTA (véase, con fecha 3-VIII-1936, minuta, copia, traslado a los jefes del establecimiento donde prestan servicio los interesados y comunicación a cada interesado, respectivamente, AGA, Educación, 5, Caja 31/6078, Exp. 14089-9; Caja 31/3830, Exp. 37 y 31/4657, Exp. 13054-6).

49 Así, por ejemplo, en una carta fechada el 27-VII-1936, Orueta se dirigía al deán de la Catedral de Madrid (San Isidro), indicándole: "Al girar en la tarde de ayer una visita a la Catedral se observó que en una de sus habitaciones había una caja de caudales y debiendo contener valores y alhajas que no deben continuar allí dadas las condiciones del edificio, esta Dirección General de conformidad con la vigente legislación sobre la materia ha resuelto interesar a Vd. se sirva designar día y hora para proceder a abrir dicha caja y poner a salvo lo que se estime conveniente de todo cuanto contenga, siendo de advertir que si en un plazo prudencial y urgente no se recibe contestación a este oficio se procederá a tal operación con auxilio de un cerrajero". En cuanto al breve informe citado, que no tiene fecha ni firma, comenta el estado o contenido de interés del resto de los edificios citados. Por lo general, también relaciona diferente obra que debe procederse a custodiar o trasladar, aunque señalando para los conventos de las Descalzas y la Encarnación, por ejemplo, que, con independencia del destino que se diere a los edificios, sus conjuntos sean conservados como tales, debiendo ser custodiados "celosamente para mantener su integridad artística y ambiente histórico" (AGA, Educación, 5, Caja 31/6078, Exp. 14089-9).

${ }^{50}$ El preámbulo del Decreto, para explicar la medida, hacía hincapié en el "espíritu de renovación” que impulsaba al Gobierno para transformar "en realidades tangibles las orientaciones y postulados que son razón de existencia del Frente Popular" y en que dicho Cuerpo "es uno de los más necesitados de que se realce en lo futuro la misión de cultura a que está destinado, para conseguir, sobre todo, que esa cultura sea puesta al servicio de las masas populares españolas", tal como fue "el espíritu que predominó en las dos últimas Asambleas celebradas por los funcionarios de dicho Cuerpo". La Comisión Gestora, además de Navarro Tomás como presidente, también la integraban como vocales José Tudela, Luisa Cuesta, Teresa Andrés, Francisco Rocher, Ricardo Martínez y Ramón Gutiérrez, y como secretario Juan Vicens de la Llave (Decreto del MIPBA de 5-VIII-1936, Gaceta de Madrid, n. ${ }^{\circ}$ 219, de 6-VIII-1936, p. 1086). Ricardo de Orueta procedió a trasladar a Navarro Tomás y al resto de los integrantes de la Comisión Gestora el contenido del Decreto el mismo día de su inserción en la Gaceta (AGA, Educación, 5, Caja 31/4656, Exp. 13054-1).

51 Así, pongamos como ejemplo, José Alaminos se dirigía el 3-VIII-1936 a Orueta exponiéndole que, habiendo sido incautado en Madrid por las milicias "el palacio-museo, sito en la calle de Serrano número 114, de esta capital, en el que se conservan incalculables obras de arte de un valor artístico e histórico apreciado en el mundo entero del arte, en el que el que suscribe viene colaborando hace más de treinta años, como pintor restaurador de dicho museo", suplicaba que "con la mayor urgencia se haga cargo de esta inmensa colección de obras artísticas el Patronato Nacional Artístico, al propio tiempo que nombre con carácter de conservador permanente al solicitante, cuyos merecimientos 
salvaguarda del patrimonio histórico-artístico y documental, no tardando en tramitar con la Dirección General de Seguridad unos carnés de identificación para todo el personal de Archivos, Bibliotecas y Museos que intervenían en estas labores ${ }^{52}$.

Consecuentemente con toda esta actuación, el presidente de la Comisión Gestora también fue informando a Orueta de los acuerdos adoptados en sus reuniones desde comienzos de agosto. El primero de ellos consistió en ofrecer a la JIPTA "equipos especializados, que están ya dispuestos, formados por el personal del Cuerpo de Archiveros, Bibliotecarios y Arqueólogos, a fin de que presten sus servicios técnicos en todos los trabajos derivados de la incautación de fondos documentales, bibliográficos, artísticos y arqueológicos", y, el segundo, en enviar una circular a todos los funcionarios del citado Cuerpo "residentes en las provincias sometidas al Gobierno legítimo, ordenándoles se pongan en relación con el representante de esa Junta en su localidad ofreciéndoles sus servicios personales y los locales de que dispongan para todas las tareas necesarias derivadas de la incautación de fondos documentales, bibliográficos y artísticos" 53 . Paralelamente, la Comisión Gestora incluso publicó un anuncio en la prensa llamando a los miembros del Cuerpo a "prestar su colaboración en el trabajo de inventario y organización de los fondos artísticos, documentales y bibliográficos procedentes de edificios incautados y que tiene a su cargo la Junta de Defensa del Tesoro Artístico" 54 . Y, su presidente, completó la oferta e indicaciones de personal disponible para tales labores, con el envío a Orueta de "la lista de las personas, que a juicio de esta Comisión Gestora pueden, por su formación y por sus ideas políticas, desempeñar el cargo de Delegados de la Junta de su digna presidencia"55.

Asimismo, Navarro Tomás no tardaría en ir dejando constancia al responsable de la DGBA de los fondos de archivos y colecciones bibliográficas, procedentes de las incautaciones de edificios efectuadas por la JIPTA, que ésta había ido remitiendo a la Comisión Gestora durante el mes de agosto; material que había procedido a depositar y custodiar en la Biblioteca Nacional ${ }^{56}$. Aunque,

son bien conocidos de los críticos de arte y de cuantos tienen relación con las bellas artes". A lo que el 6-VIII-1936 se le contestaba, de orden de Orueta, que, habiéndose creado por los decretos de 23 julio y 1 de agosto la JIPTA, "a ella compete velar por el Tesoro Artístico Nacional", por lo que se archivaba su instancia y se le devolvían los documentos que la acompañaban (AGA, Educación, 5, Caja 31/6078, Exp. 14089-9).

52 Este tipo de "Carnet de identidad" era visado por el director general de Seguridad, haciendo constar en él que era "Concedido a los funcionarios facultativos y auxiliares del Cuerpo de Archiveros, Bibliotecarios y Arqueólogos por órdenes de 25 de julio y 8 de agosto de 1936" (Minuta con fecha de 1936 abierta y dirigida por Orueta al director general de Seguridad, remitiendo los carnés de este personal para ser visados. AGA, Educación, 5, Caja 31/4656, Exp. 13054-1.)

53 El primer y segundo acuerdo se tomaron, respectivamente, en las sesiones celebradas por la Comisión Gestora el 6 y 8 de agosto y los comunicaba Navarro Tomás a Orueta en sendos oficios fechados el 11-VIII-1936 (AGA, Educación, 5 [1.03], Caja 31/3830, Exp. 37).

${ }^{54}$ Cada uno de los funcionarios, se añadía, debía hacer saber a la Comisión las horas que podía dedicar a esos trabajos, poniéndose en contacto con las direcciones proporcionadas (véase ÁlvAREZ LoPERA, op. cit., 1982, vol. 2, p. 131 n. 3).

${ }^{55}$ Esta lista de posibles Delegados de la JIPTA, se la remitía Navarro Tomás con su oficio de 13-VIII-1936 y en ella se relacionaban, con indicación de puestos e ideas políticas conocidas, para Valencia al catedrático de Numismática Gonzalvo y para Játiva a José Chocaneli, para Alicante al catedrático Eliseo Gómez Serrano, para Murcia al bibliotecario de la Universidad Andrés Sobejano y al catedrático Cayetano Alcázar, para Málaga al arquitecto Miró y para Ciudad Real al abogado Alberto Gómez Lobo. Mas adelante, Navarro Tomás también propondrá a la Junta presidida por Orueta algunos nombres para ocupar cargos delegados, como el de Delegado de la JIPTA en Albacete, para el que proponía en su oficio de 3-IX-1936 al director del Museo Arqueológico de esa ciudad, Joaquín Sánchez, "persona que por sus conocimientos y lealtad al Gobierno legítimo cree esta Comisión ser la persona más indicada para este nombramiento" (AGA, Educación, 5 (1.03), Caja 31/3830, Exp. 37).

${ }^{56}$ El 13 de agosto, Navarro Tomás informaba al presidente de la JIPTA de que, hasta esa fecha, el Delegado de la JIPTA Antonio Rodríguez Moñino había hecho entrega a la Comisión Gestora de las siguientes colecciones que habían 
los problemas de espacio y la competencia sobre el material recogido, pronto obligarían a la Comisión a gestionar nuevos depósitos, como los locales de la Sociedad de Amigos del Arte en el mismo Palacio de Bibliotecas y Museos, o a aclarar que, el destino de los dibujos y grabados, sería la Sección de Estampas de esta Biblioteca Nacional ${ }^{57}$.

No obstante, pese a la diferente canalización posterior, la mayor parte de las actuaciones dirigidas a la protección de las obras de arte y de los bienes bibliográficos y documentales, se emprendieron conjuntamente. Así, para dar una idea más completa de las formas de recabar información, de las intervenciones directas y de la propia interrelación entre las labores de la Comisión Gestora y la JIPTA, sobre todo resultan de gran interés los informes sobre los viajes y trabajos realizados por los comisionados. Entre ellos, destaca el documento remitido por Ramón Iglesias, vocal de la primera y ayudante de la segunda, en torno a sus viajes de reconocimiento de la situación del patrimonio artístico y documental, realizados a partir del 21 de agosto a Sigüenza y a Guadalajara y sus pueblos limítrofes ${ }^{58}$; así como, en el mismo sentido, los detallados informes

quedado custodiadas en la B.N.: la Biblioteca de las Comendadoras de Santiago; el Archivo del Marqués de Mirasol, procedente del mismo convento; la Biblioteca del Conde de la Viñaza y el Archivo y Biblioteca del Convento de las Trinitarias de Lope. El 31 de agosto, Navarro Tomás volvía a informar a Orueta de que, desde su última comunicación en este sentido del 13 de agosto, la JIPTA había remitido a la Comisión Gestora los siguientes fondos procedentes de edificios incautados: el Archivo-Biblioteca del Duque de Medinaceli; la Biblioteca del Colegio de Marianistas de la calle de Castelló; la Biblioteca del Colegio de los Escolapios de San Antón; la Biblioteca del Duque de T'Serclaes; el Archivo de las Órdenes Militares y la Biblioteca de Roque Pidal, todos ellos custodiados en la B.N., donde se iban inventariando y clasificando, esperándose poder poner en breve algunos de ellos al servicio del público (Oficios de 13 y 31-VIII-1936, AGA, Educación, 5 [1.03], Caja 31/3830, Exp. 37).

57 El 22-VIII-1936, Orueta trasladaba a Navarro Tomas la resolución del MIPBA de que las obras de arte y cuanto contuvieran los citados locales de la Sociedad, se recogiese e inventariase, instalándolo en la sala de juntas y biblioteca, procediéndose a sellar y lacrar esta dependencia, entregándose las llaves de todos los locales de la Sociedad a la Comisión Gestora, para que ésta los utilizase con carácter provisional "para depositar los libros y documentos de que se incaute y así lo estime conveniente." Por otro lado, el 3-IX-1936, Navarro Tomás informaba a Orueta de que la Comisión habían comenzado a recibir los libros de la Biblioteca particular "Sánchez Toca", que como otros tantos de diversas procedencias estaban siendo acogidos en los depósitos de la Biblioteca Nacional, añadiendo: "Mas como entre los fondos de dicha Biblioteca particular, existe asimismo un número estimable de dibujos y grabados y conocemos el acertado criterio de esa Junta, favorable a que los fondos incautados vayan siempre a la colección pública más indicada para acogerlos, dichas estampas deberían venir asimismo a la Biblioteca Nacional. Nadie ignora que la sección de estampas y dibujos de la Biblioteca, es el núcleo más importante de España en éste aspecto y la única colección pública de Madrid, teniendo por tanto todos los títulos para merecer que se enriquezcan sus fondos, con los que aporten las incautaciones que se realizan./ Por otra parte la Biblioteca Nacional, tiene en tal estima esta sección suya, que hace varios años ha llevado a cabo un plan de reforma total que culminará con la ejecución, ya comenzada, de un depósito moderno especial y la habilitación de nuevas salas según proyectos del Arquitecto D. Luis Moya./ Esta Comisión Gestora, cree que la fuerza de éstas razones, será cordialmente reconocida por esa Junta de su digna presidencia y de éste modo las estampas y dibujos de la Biblioteca antes mencionada, así como cualquier otro fondo semejante, serán enviados en lo sucesivo a su natural destino, que es la Sección de estampas de ésta Biblioteca Nacional" (Oficios, respectivamente, de 22-VIII-1936 y 3-IX-1936, AGA, Educación, 5 (1.03), Caja 31/3830, Exp. 37).

58 En su primer informe, fechado en Madrid el 22-VIII-1936, Ramón Iglesias da cuenta del viaje realizado a Sigüenza el día anterior en compañía de Antonio Pérez, secretario general del Sindicato Nacional Ferroviario, y José García, secretario del director general de Bellas Artes; centrándose especialmente en relatar el estado en el que se encuentran los edificios y colecciones, el desempeño de la autoridad y las actuaciones emprendidas en torno a la Catedral, el Seminario-Palacio Episcopal y el Convento de las Ursulinas. El segundo informe, fechado el 29-VIII-1936, relataba los viajes realizados en los días posteriores a Guadalajara capital y varios de sus pueblos limítrofes (Cifuentes, Torija, Horche, Armuña, Pastrana, Jadraque, Yunquera, Humanes, Torres del Burgo y Cogolludo) y la situación encontrada respecto al patrimonio en cada uno. Navarro Tomás remitió a Orueta estos informes, respectivamente, el 26 y 29-VIII1936, contestándole éste el 28-VIII-1936 y el 1-IX-1936 que se daba por enterado y aplaudía la actuación de Iglesias (AGA, Educación, 5 (1.03), Caja 31/3830, Exp. 37). 
sobre la recogida de obras que, desde la misma fecha, había iniciado en Alcalá de Henares -por indicación de la JIPTA- el funcionario facultativo José María Lacarra ${ }^{59}$.

Sobre estos últimos trabajos, aunque iniciados anteriormente, sería al siguiente director general, Josep Renau, a quien ya se diera cuenta; al mismo tiempo que también fue él el informado de los nuevos fondos, procedentes de diferentes incautaciones, recibidos por la Comisión Gestora hasta el 22 de septiembre. Igualmente, ya fue el joven cartelista valenciano quien aprobó la actuación y destinos dados por la Comisión a ese material ${ }^{60}$. Ésta, pues, se había convertido en una dinámica estructura ${ }^{61}$, cuyo presidente, Navarro Tomás, no es extraño que en febrero de 1937 fuera elegido vicepresidente del Consejo Central de Archivos, Bibliotecas y Tesoro Artístico (CCABTA), dependiente de la DGBA y que presidió Renau en función de su cargo. Este órgano fue desde ahora el que vino a estructurar y centralizar los esfuerzos, subdividido las tareas en las tres Secciones a las que refería su nombre (Archivos, Bibliotecas y Tesoro Artístico); las cuales, a su vez, se estructuraban en Subsecciones ${ }^{62}$. En abril, se creó la Junta Central del Tesoro Artístico

59 Lacarra emitió dos extensas Notas-informe, fechas en Alcalá de Henares el 5 y 25-IX-1936. En la primera comienza indicando que su labor se había iniciado tras ser designado por la JIPTA, el 21 de agosto, "para recoger los fondos documentales, bibliográficos y artísticos de Alcalá de Henares". Para entonces, el Ayuntamiento ya se había hecho cargo de las llaves de los conventos, en su mayor parte saqueados durante lo sucesos de hacía un mes en Alcalá, y había recogido algunas obras. El edificio de éste y el convento de las Bernardas eran los lugares donde había trasladado las obras recogidas (al final también se aludía a las gestiones realizadas para ampliar los depósitos con el cuartel de Mendigorría), que luego se seleccionarían y ordenarían; ofreciéndose un detallado comentario sobre lo recogido y el estado en que quedaban los conventos de las Bernardas, las Magdalenas, las Catalinas, las Juanas (San Juan de la Penitencia), las Carmelitas de la Imagen y los Filipenses (Oratorio de San Felipe); el Colegio de los Escolapios, Santa María, la Magistral y el Hotel Laredo. El segundo informe, presentado junto al auxiliar Carlos Rodríguez Juliá, se refería a los objetos artísticos recogidos en Alcalá de Henares entre el 7 y el 25 de septiembre, detallándose lo realizado en el Seminario, las Úrsulas, la parroquia de Santiago, las Beatas de San Diego, las Filipensas, Santa Clara, las Catalinas, las Magdalenas, las Carmelitas de Afuera, la Ermita del Cristo de los Doctrinos, el Hospital de Antezana, el Colegio de Adoratrices y la Magistral, así como se comentaba que se había iniciado el inventario de los objetos recogidos en las Bernardas, de los que se llevaban registrados 700. Estos informes dieron origen a la felicitación por parte de presidente de la Comisión Gestora tanto al Ayuntamiento de Alcalá y su concejal José Antonio Cumplido (oficio dirigido al primero de 31-VIII-1936), como al propio Lacarra y a Rodríguez Juliá (9-IX-1936). (AGA, Educación, 5 [1.03], Caja 31/3830, Exp. 37.)

${ }^{60}$ Navarro Tomás, con fecha 22-IX-1936, se dirigía al Presidente de la JIPTA y director general de Bellas Artes, indicándole que, desde su última comunicación en este sentido, de 31-VIII-1936, hasta la fecha, se habían recibido los siguientes fondos procedentes de edificios incautados y enviado por la JIPTA: las Bibliotecas de Sánchez Toca, de la Condesa Viuda de Paredes de Nava, de la Duquesa de Almenara Alta, de el Marqués de Vega-Inclán y de los Benedictinos de Montserrat; así como parte de la Biblioteca de Lázaro Galdeano y los Mapas de la Sociedad Patronal. A ello se añadía la recepción de un donativo de Cultura Popular, consistente en 312 grabados, un libro de horas, tres ejecutorias miniadas y 25 libros corrientes (todo ello procedente del Palacio de Revillagigedo); y todos los fondos habían pasado a custodiarse en la Biblioteca Nacional, salvo las ejecutorias, enviadas al Archivo Histórico Nacional. A esta comunicación respondería Renau, el 25-IX-1936, significando la gratitud de la DGBA a Cultura Popular por el donativo y aprobando el destino dado por la Comisión a los fondos (AGA, Educación, 5 [1.03], Caja 31/3830, Exp. 37).

${ }^{61}$ Como caracterización de conjunto de la labor de protección del patrimonio bibliográfico y documental, que, como indica, Álvarez Lopera, viene a quedar oscurecida "por la más espectacular de protección del tesoro artístico" y "suele quedar relegada a mero apéndice de aquella", véase su introducción en Op. cit., 1982, vol. 2, pp. 131-139.

${ }^{62}$ Según el artículo primero del Decreto que creó el CCABTA, éste era dependiente de la DGBA y tenía como misión coordinar la labor de todos los establecimientos y servicios relacionados con las tres secciones en las que se dividía, definiéndose en los artículos siguientes la constitución, funciones y subsecciones de cada una, que además debían elaborar un reglamento por el que se regirían. En cuanto a la Sección de Tesoro Artístico, de ella pasaban a depender "todos los Museos Artísticos y Arqueológicos dependientes del Estado, así como los servicios hasta hoy regidos por la Junta Superior del Tesoro Artístico y de la Incautación y Protección del Patrimonio Artístico"; además quedaba compuesta por las Subsecciones de Conservación de Monumentos Histórico-artísticos, Excavaciones, Organización de Museos, Adquisiciones, Fichero Artístico, Arte Contemporáneo y Difusión y Fomento de la Cultura Artística; quedando la citada Junta 
(JCTA), dependiente del CCABTA y presidida por Timoteo Pérez Rubio, a la que se le dotó de la capacidad tanto de proponer la ratificación o reorganización de las Juntas Delegadas que ya existían en diferentes ciudades, como de crear otras nuevas en las provincias donde no las hubiera o en otras localidades donde excepcionalmente se hiciera necesario implantar Subjuntas ${ }^{63}$. Renau, pues, además de la dirección centralizadora y reestructuradora, respecto a los cargos y cometidos, había dado cierto giro hacia el dinamismo y la modernización, ya que siempre buscó hacer más presentes a los jóvenes creadores con experiencia burocrática relacionada con las Bellas Artes.

En cualquier caso, habían pasado los tiempos de la prudente y equilibrada actuación de Ricardo de Orueta, quien posiblemente tampoco habría podido dar mucho más de sí en esos frenéticos tiempos bélicos. De manera que, tras el cambio de Gobierno producido el 4 de septiembre de 1936, que aparejó la presentación de su dimisión cinco días después al nuevo ministro del MIPBA, Jesús Hernández, corrió el malagueño una suerte parecida a la que tuvieron la mayor parte de los intelectuales trasladados en noviembre a Valencia. Sin embargo, no estuvo allí mucho tiempo, pues a mediados de julio de 1937, tras informar al mismo Navarro Tomás -también secretario de la JAE- de su intención de reinstalarse en el CEH para continuar sus trabajos de escultura, regresó a Madrid, donde moría el 10 de febrero de 1939, muy poco antes de la entrada de Franco, como ya hemos relatado en otro lugar. Nos hemos referido también en ese mismo trabajo a cómo, a partir de entonces, aunque ocasionalmente se le recordó como erudito de la historia de la escultura, su fortuna crítica como pionero y reiterado gestor de la política de Bellas Artes republicana no le fue muy favorable, hasta que empezara su lenta revisión y recuperación a partir del término de la dictadura ${ }^{64}$.

Fecha de recepción: 4-XII-2008

Fecha aceptación: 22-II-2009

\footnotetext{
de Incautación y Protección "adscrita, previa reorganización por el Director General de Bellas Artes, a la Subsección de Adquisiciones de la Sección de Tesoro Artístico". (Decreto del MIPBA de 16-II-1937, Gaceta de la República, n. ${ }^{\circ}$ 48, de 17-II-1937, pp. 847-848). Por otro lado, dicho CCABTA vino a fijar con mayor precisión sus atribuciones y actividades en la Orden del MIPBA de 5-IV-1937 (Gaceta de la República, n. ${ }^{\circ} 109$, de 19-IV-1937, p. 282) y tuvo varios reajustes en el mes de octubre, al tiempo que se nombraban sus cargos de presidentes y secretarios de las secciones y subsecciones. Así, tras la presidencia y vicepresidencia generales ocupadas por Renau y Navarro Tomás, se nombraba presidente de la Sección de Archivos a Agustín Millares, de la de Bibliotecas a Navarro Tomás y de la de Tesoro Artístico a Ángel Ferrant; así como secretario general de todo el Consejo a José Giner Pantoja. Para las citadas Subsecciones de la Sección de Tesoro Artístico, se nombraban secretarios, respectivamente, a Alejandro Ferrant, Juan Carriazo, Mariano Rodríguez Orgaz, Timoteo Pérez Rubio, Manuel Gómez Moreno, Roberto Fernández Balbuena y Pablo Gutiérrez Moreno (Orden del MIPBA de 25-X-1937, Gaceta de la República, n. ${ }^{\circ} 301$, de 28-X-1937, pp. 368-369).

${ }^{63}$ Orden del MIPBA de 5-IV-1937 (Gaceta de la República, n. ${ }^{\circ}$ 109, de 19-IV-1937, pp. 282-283).

${ }^{64}$ Véase CABAÑas Bravo, M.: "Ricardo de Orueta...", op. cit., 2009. Sobre la última etapa de Orueta en Madrid, entre 1937 y 1939, es de especial interés la correspondencia que mantuvo con Navarro Tomás, custodiada en la Residencia de Estudiantes (JAE/168/23).
} 


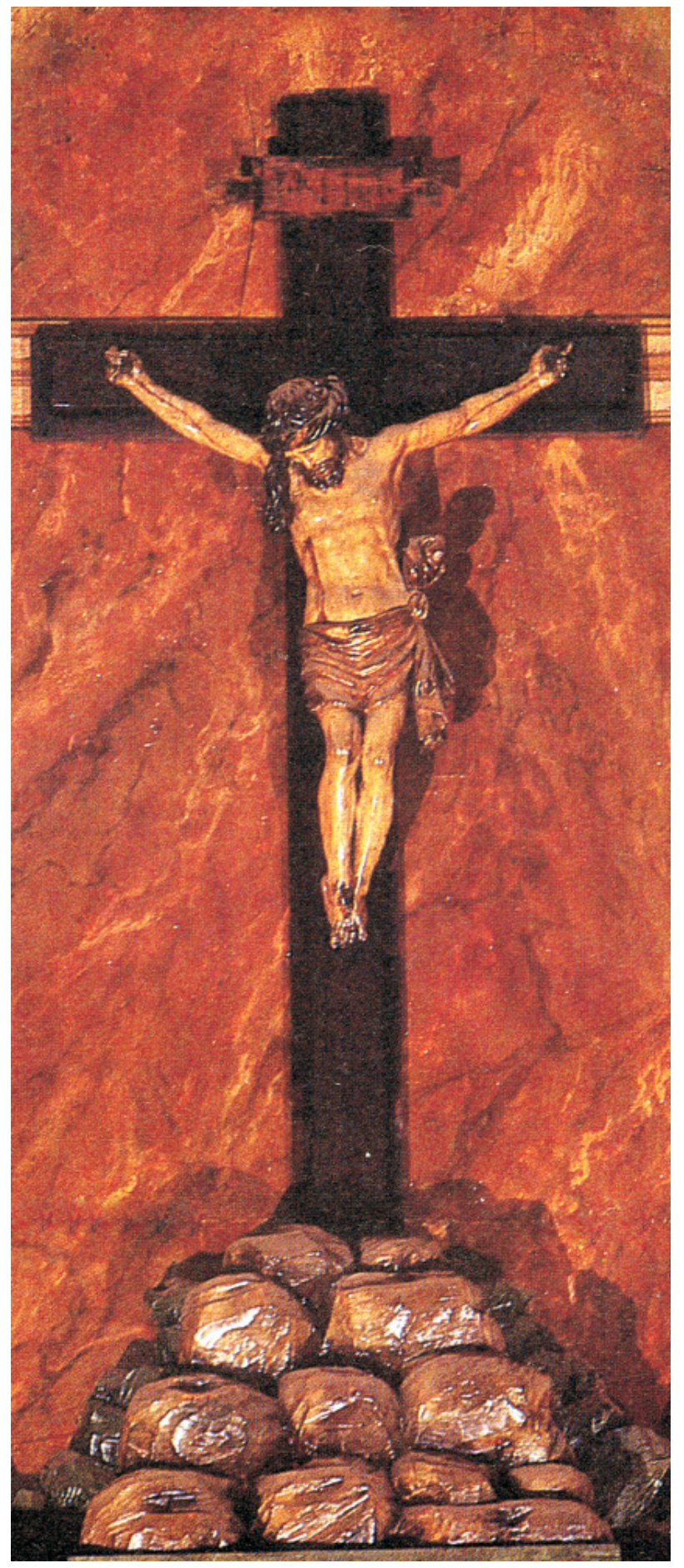

Fig. 1. Francisco Giralte, círculo de. Crucificado. Valladolid. Palacio Real. 